\title{
Phytopathology
}

\section{Cultural and Genetic Approaches to Manage Aflatoxin Contamination: Recent Insights Provide Opportunities for Improved Control}

\author{
Peter S. Ojiambo, ${ }^{\dagger}$ Paola Battilani, Jeffrey W. Cary, Burt H. Blum, and Ignazio Carbone
}

First and fifth authors: Center for Integrated Fungal Research, Department of Entomology and Plant Pathology, North Carolina State University, Raleigh 27695; second author: Department of Sustainable Crop Production, Università Cattolica del Sacro Cuore, Via Emilia Parmense 84, 29122 Piacenza, Italy; third author: U.S. Department of Agriculture-Agriculture Research Service, SRRC, New Orleans, LA 70124; and fourth author: Department of Plant Pathology, University of Arkansas, Fayetteville 72701.

Accepted for publication 4 June 2018.

\begin{abstract}
Aspergillus flavus is a morphologically complex species that can produce the group of polyketide derived carcinogenic and mutagenic secondary metabolites, aflatoxins, as well as other secondary metabolites such as cyclopiazonic acid and aflatrem. Aflatoxin causes aflatoxicosis when aflatoxins are ingested through contaminated food and feed. In addition, aflatoxin contamination is a major problem, from both an economic and health aspect, in developing countries, especially Asia and Africa, where cereals and peanuts are important food crops. Earlier measures for control of A. flavus infection and consequent aflatoxin contamination centered on creating unfavorable environments for the pathogen and destroying contaminated products. While development of atoxigenic (nonaflatoxin producing) strains of $A$. flavus as viable commercial biocontrol agents has marked a unique advance for control of aflatoxin contamination, particularly in Africa, new insights into the biology and sexuality of $A$. flavus are now providing opportunities to design improved atoxigenic strains for sustainable biological control of aflatoxin. Further, progress in the use of molecular technologies such as incorporation of antifungal genes in the host and host-induced gene silencing, is providing knowledge that could be harnessed to develop germplasm that is resistant to infection by A. flavus and aflatoxin contamination. This review summarizes the substantial progress that has been made to understand the biology of A. flavus and mitigate aflatoxin contamination with emphasis on maize. Concepts developed to date can provide a basis for future research efforts on the sustainable management of aflatoxin contamination.
\end{abstract}

Aspergillus section Flavi is composed of 27 fungal species (Carvajal-Campos et al. 2017) that are primarily saprobic in nature with a global distribution and are often found residing in soil. Two members of section Flavi, A. flavus and A. parasiticus, are economically important pathogens of agricultural crops due to their ability to produce aflatoxins. Based on the size of sclerotia, A. flavus is classified as either an L morphotype with sclerotia of $>400 \mathrm{~mm}$ in diameter or an S morphotype with sclerotia of $<400 \mathrm{~mm}$ (Cotty 1990; Horn 2005). A. flavus $\mathrm{L}$ and $\mathrm{S}$ morphotypes produce primarily aflatoxin $\mathrm{B}_{1}\left(\mathrm{AFB}_{1}\right)$ and $\mathrm{B}_{2}$, while $A$. parasiticus produces both $B_{1}$ and $B_{2}$ and $G_{1}$ and $G_{2}$ aflatoxins. However, some $\mathrm{S}$ morphotypes of A. flavus also produce both $\mathrm{B}$ and $\mathrm{G}$ aflatoxins (Probst et al. 2014). The B aflatoxins have a cyclopentenone ring that is fused to the lactone ring of the coumarin moiety and have a strong blue fluorescence when exposed to ultraviolet (UV) light. The $\mathrm{G}$ series of aflatoxins contain a fused lactone ring and fluoresce greenish yellow under UV light (Kensler et al. 2011). Aflatoxins are polyketide-derived secondary metabolites produced by these fungi

${ }^{\dagger}$ Corresponding author: P. S. Ojiambo; E-mail: peter_ojiambo@ncsu.edu

(C) 2018 The American Phytopathological Society during growth on a wide range of agricultural products, both preand postharvest, especially cereals and nuts, and are toxic, carcinogenic, and mutagenic agents. The initial recognition of the importance of aflatoxin can be traced back to the epidemic of 'Turkey X' disease in England in 1960 that resulted in deaths of tens of thousands of turkey poults, ducklings, and chicks fed on diets containing certain lots of peanut meal originating from South America (Blount 1961). Subsequent investigations showed that the toxicity was due to the presence of A. flavus when extracts of the fungal cultures isolated from the meal were able to induce the 'Turkey X' syndrome. Consequently, the term 'Aflatoxin' i.e., A. flavus toxin, was coined and assigned to the toxic metabolite (Kensler et al. 2011).

Aflatoxins are found in several agricultural products including maize, peanuts, rice and tree nuts and consumption of contaminated products result in a range of health disorders. Aflatoxicosis arises when humans and animals ingest food or feed products contaminated with aflatoxins. In addition to its primary concern as a potent mycotoxin producer, A. flavus is also an opportunistic pathogen and invasive growth of the fungus in animals and humans results in aspergillosis, a condition that can be fatal in humans with a compromised immune system (Paulussen et al. 2016). Aflatoxin thus poses as a serious health risk in developing countries in Asia 
and Africa where maize, peanuts, and rice constitute a major part of the staple diets for the population. Further, although the high polarity and lipophobicity of aflatoxins have led to the perception that peanut oil is free of aflatoxins, contaminated oils are frequently sold in local markets in many developing countries where highly contaminated peanuts may be the raw material for locally produced oil (Shephard 2018). The situation is further complicated by reports of organoleptic properties of unrefined oil being desirable in some local communities (Ling et al. 1968). The latter has resulted in renewed calls to monitor locally produced oils in developing markets for aflatoxin contamination and the need to formulate maximum limits for aflatoxins in peanut oil consumed in developing countries to protect consumers from exposure to this often-ignored area of food safety (Shephard 2018).

A working group on public health strategies estimated that about 5 billion people globally were at a risk of chronic exposure to aflatoxins in developing countries due to either the absence of regulatory limits, inability to enforce established limits, or lack of resources, technology, and infrastructure necessary for routine food monitoring (Strosnider et al. 2006). Previous review papers (Kensler et al. 2011; Wu et al. 2014) summarized the adverse human health effects of aflatoxin exposure. The reader is directed to these papers for a more in-depth discussion of the toxicological mechanisms of aflatoxin in the body, and the epidemiology of aflatoxin-related illness. Chronic aflatoxicosis due to long-term exposure to low levels of aflatoxin results in cancers and especially liver cancer (Wu et al. 2014). Suffice it to say, the dose and duration of exposure to aflatoxin determines the extent of toxicity in individuals and has a cumulative effect on the risk of developing liver cancer. Aflatoxin exposure has also been linked to modulation of human immunity (Jolly et al. 2008) and childhood stunting, with the latter being associated with effects such as increased vulnerability to infectious diseases and cognitive impairments that last well beyond childhood (Khlangwiset et al. 2011). Acute aflatoxicosis due to the consumption of foods contaminated with very high levels of aflatoxin results in vomiting, abdominal pain, pulmonary edema, and fatty infiltration and necrosis of the liver (Shank et al. 1971). Ingestion of large doses of aflatoxin can also result in direct liver damage and death. While, cases of acute aflatoxicosis are relatively infrequent, reports of death and illness are usually from developing countries in Asia and Africa. In the 1970 s, consumption of heavily molded maize caused a putative acute aflatoxin poisoning in western India that resulted in 97 fatalities (Bhat and Krishnamachari 1977). Later in the 1980s, consumption of maize highly contaminated with aflatoxin was linked to an outbreak of acute aflatoxicosis in Kenya with a $20 \%$ fatality among hospital admissions (Ngindu et al. 1982). In 1995, consumption of noodles contaminated with aflatoxin resulted in acute aflatoxicosis in children in Malaysia (Lye et al. 1995). A 2004 outbreak in Kenya is the largest documented case of acute aflatoxicosis, which resulted in 317 cases and 125 fatalities (Lewis et al. 2005). This outbreak was later reported to be due to an S strain of A. flavus that had not been previously found in Africa (Probst et al. 2007). More recently, acute aflatoxicosis due to ingestion of large quantities of aflatoxin was linked to 14 fatalities in Tanzania (Mytox 2016).

Besides presenting a serious public health problem, contamination of food by aflatoxins also poses a considerable economic hurdle in many developing countries in Africa and Asia whose trade balance is based on the exportation of cereals such as maize, peanut, and rice (Ladeira et al. 2017). Regulatory guidelines for levels of aflatoxins in food, feed, and milk have resulted in direct loss of produce or market value of crops contaminated with aflatoxin. The U.S. Food and Drug Administration has imposed stringent regulations on levels of aflatoxin at $20 \mathrm{ppb}$ in food and feed, while the European Union (EU) has set the limit much lower, at $4 \mathrm{ppb}$. Based on these regulatory guidelines, an earlier World Bank study estimated losses over US\$670 million annually in Africa due to requirements to comply with the EU standards for all food exports (Otsuki et al. 2001). However, estimates based on actual aflatoxin levels in the foodstuffs and actual volumes of trade of different foodstuffs between Africa and the EU were subsequently revised downward. For example, it was estimated that the cost to African exporters to meet the EU standard would be about $\$ 40$ million annually for peanut ( $\mathrm{Wu}$ 2004). Maize and peanuts are two important agricultural commodities relative to production, consumption, and trade in Africa and aflatoxin contamination will continue to have significant economic and public health impacts on affected countries. Further, food scarcity frequently forces people to consume contaminated foods because no other food options are available and commodities rejected from premium markets are often processed and offered at low prices in informal markets which further compounds exposure to aflatoxin.

This review highlights recent research conducted to facilitate our understanding of the biology and characteristics of A. flavus and application of this knowledge to improve the management of aflatoxin contamination with emphasis on maize. We specifically highlight the following: (i) the epidemiology of A. flavus and how it contributes to aflatoxin contamination, (ii) the mechanisms of biological control of aflatoxin contamination using atoxigenic strains and sexual reproduction in A. flavus and its potential role in improving biological control, and (iii) the use of conventional and molecular breeding approaches for resistance to A. flavus infection and aflatoxin contamination (Fig. 1). Finally, we conclude by highlighting how these evolving aflatoxin management strategies can be applied to other mycotoxin producing fungi.

\section{EPIDEMIOLOGY AND DISEASE CYCLE OF A. FLAVUS}

Disease and life cycle of $A$. flavus and factors affecting infection and aflatoxin contamination. A. flavus is distributed globally and aflatoxin outbreaks can occur in unexpected geographic areas when weather conditions become favorable, as has been observed in Europe (Dobolyi et al. 2013; Piva et al. 2006). Sclerotia in soil and mycelia and sclerotia in crop debris are efficient overseasoning structures that generate the primary inoculum for ear infection (Angle et al. 1989). In maize, silk emergence triggers the start of host susceptibility to A. flavus, with the browning of silks enhancing the infection efficiency of airborne conidia (Payne and Widstrom 1992). Fungal colonization of silks and kernel surfaces on the ear continues during the growing season (Marsh and Payne 1984), while kernel invasion is commonly observed at the dent stage (Weber and Bleiholder 1990). Damage of ears by insect pests such as the European corn borer, Ostrinia nubilalis, can significantly contribute to kernel invasion (Widstrom 1979).

A. flavus was largely thought to propagate asexually, a mode of reproduction that involves production of conidia that are dispersed by wind and insect leading to infection of ears through the silks (Fig. 2 ). However, the fungus is also capable of reproducing sexually (Horn et al. 2009b) and parasexually (Papa 1973). The fungus is heterothallic and sexual reproduction occurs between two individuals with opposite mating types, MAT1-1 and MAT1-2 idiomorphs, resulting in the formation of asci bearing ascospores (Fig. 2). Parasexual genetic exchange occurs only when hyphae of an individual strain come into contact with hyphae of another individual that share the same heterokaryon incompatibility alleles (Fig. 2). While the latter mode of reproduction has been demonstrated in the laboratory and some evidence suggests that it could occur in nature, unequivocal evidence for parasexual reproduction and its role under field conditions is still lacking.

A. flavus is active between 10 and $45^{\circ} \mathrm{C}$ and all the stages of the infection cycle, from sporulation to host infection can take place within this range of temperature (Sanchis and Magan 2004). Water content in grain is often suitable for the fungus until a water 
activity $\left(\mathrm{a}_{\mathrm{w}}\right)$ of 0.73 is reached, which is equivalent to about $14 \%$ kernel moisture content (Battilani et al. 2011). In contrast, the range of conditions suitable for aflatoxin production is narrower, with temperatures between 15 and $35^{\circ} \mathrm{C}$ and $\mathrm{a}_{\mathrm{w}} \geq 0.85$ (Sanchis and Magan 2004). Water activity between 0.95 and 0.99 has been reported as optimal for aflatoxin production based on in vitro assays (Battilani et al. 2013; Sanchis and Magan 2004). However, field surveys that account for the dynamic of aflatoxins during the maize growing season show that aflatoxin increases significantly when kernel moisture is below $28 \%$ or $\mathrm{a}_{\mathrm{w}} \leq 0.95$ (Battilani et al. 2008, 2011; Hruska et al. 2013). A field trial, conducted to clarify the apparent disagreement between in vitro and in field data, showed that the correlation between $\mathrm{AFB}_{1}$ production rate and $\mathrm{a}_{\mathrm{w}}$ is positive when $\mathrm{a}_{\mathrm{w}}>0.95$, but it is negative when $\mathrm{a}_{\mathrm{w}}<$ 0.95 (Giorni et al. 2016). Besides $a_{w}$, other factors such as crop growth stage, physiology, active defenses or grain composition are likely to influence the dynamics of aflatoxin production during the growing season. The ability of $A$. flavus and other ear rot fungi such as Fusarium verticillioides, to utilize carbon sources at different temperatures and $\mathrm{a}_{\mathrm{w}}$ regimes could also influence the dynamics of aflatoxin contamination during crop growth. A. flavus and F. verticillioides utilizes carbon sources optimally at 30 and $20^{\circ} \mathrm{C}$, respectively, in an $\mathrm{a}_{\mathrm{w}}$ range of 0.87 to 0.98 (Giorni et al. 2009a). The dominance of $A$. flavus at $30^{\circ} \mathrm{C}$, especially at low $\mathrm{a}_{\mathrm{w}}$, and the dominance of $F$. verticillioides at $20^{\circ} \mathrm{C}$, mainly at $0.95 \mathrm{a}_{\mathrm{w}}$, has been confirmed by niche overlap indexes. When conditions are not very warm and dry in the field, A. flavus is often outcompeted by
F. verticillioides, even if maize ears are artificially inoculated. Thus, in the presence of $F$. verticillioides, A. flavus will not necessarily be dominant in maize ears irrespective of a high initial inoculum concentration and thus, aflatoxin contamination is also likely to be limited.

A multifaceted response of $A$. flavus following infection of maize ears has been reported in several studies (Battilani et al. 2008; Giorni et al. 2009b; Lahouar et al. 2016) and all these studies implicate ecological conditions as the main driving factors. The dynamics of $\mathrm{a}_{\mathrm{w}}$ in grains, as influenced by host genotype, duration of hybrid maturity, and air temperature and humidity/rainfall during the growing season, determines the competitiveness of $A$. flavus against other co-occurring ear rot fungi. In warm and dry seasons, A. flavus is the dominant fungal species in maize kernels (Battilani et al. 2008; Giorni et al. 2009b; Lahouar et al. 2016; Piva et al. 2006) and this is associated with high levels of aflatoxin contamination in the field (Scheidegger and Payne 2005). It is important to note that variation between the day and night temperature is more important than the mean temperature for aflatoxin production, with more variation enhancing aflatoxin contamination (Criseo et al. 1990). This observation has been supported by data on maize from aflatoxin outbreaks that occurred in 2003 and 2012 in Italy. Severe outbreaks of aflatoxin contamination in maize occurred in Europe in 2012. However, aflatoxin contaminations in Italy were more consistent in 2012 than in 2003 and a close examination of weather data showed less variation between day and night temperatures in 2012 than in 2003 (P. Battilani, personal communication).
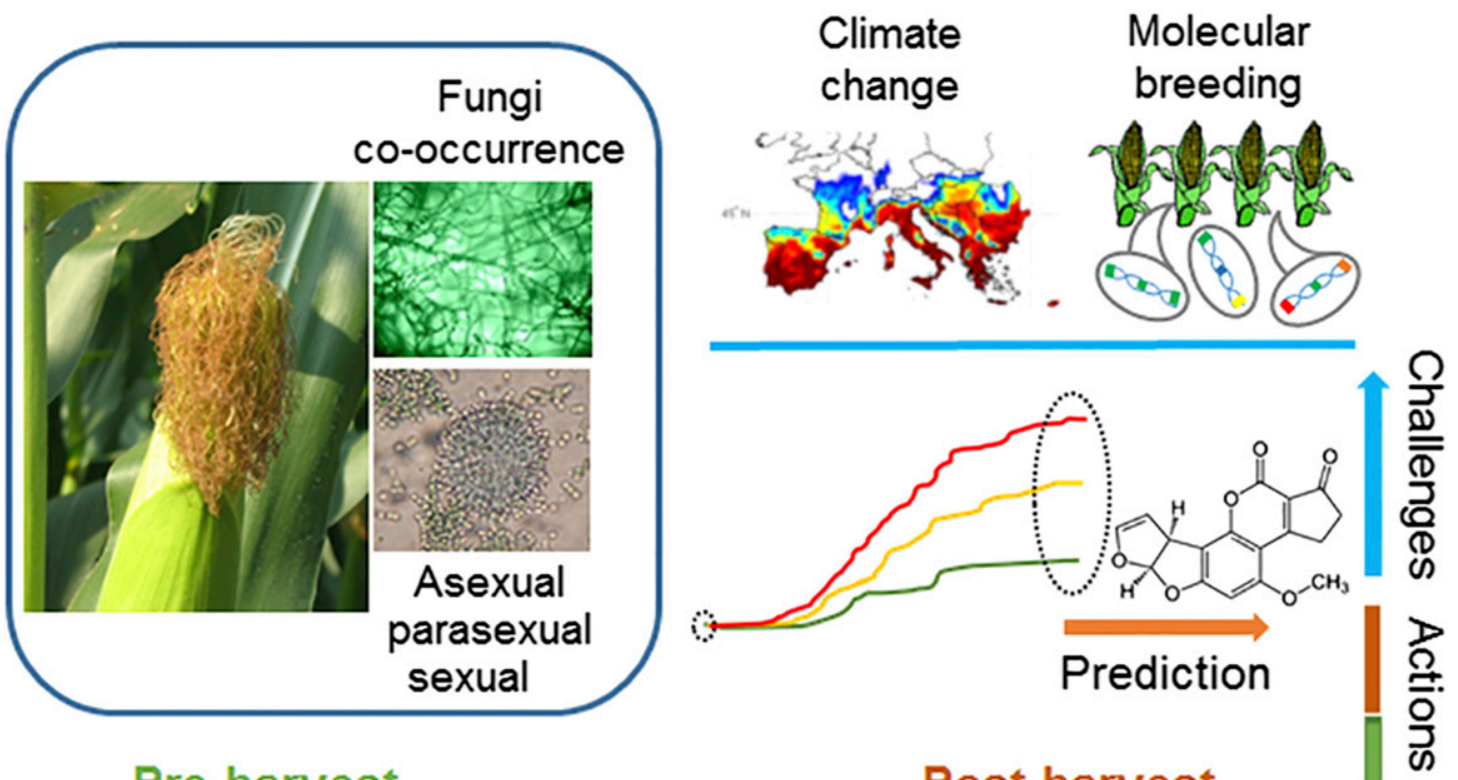

Pre-harvest
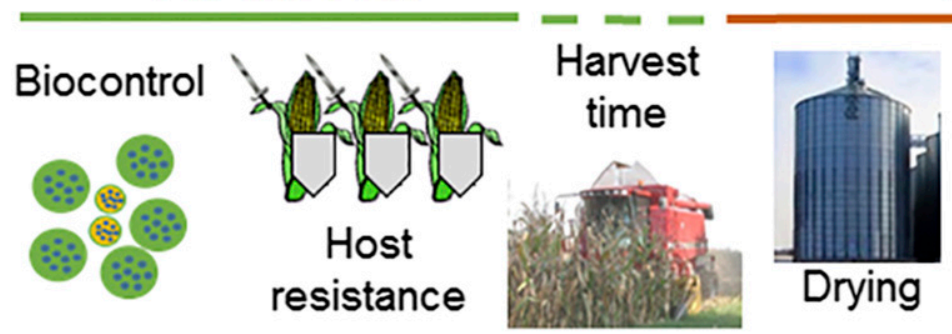

Post-harvest
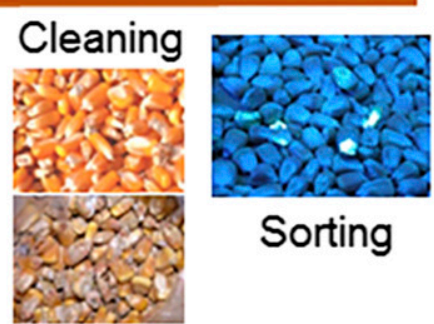

Sorting

\section{FIGURE 1}

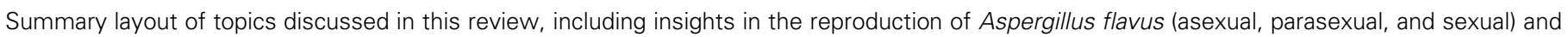

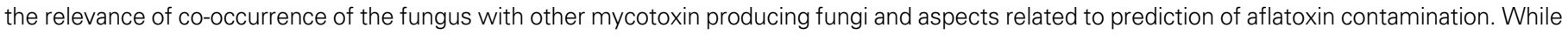

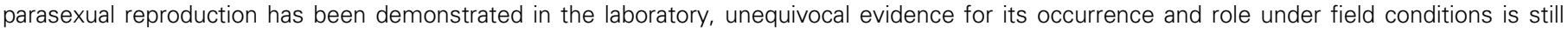

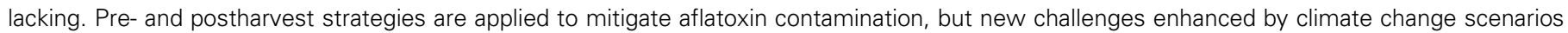
need to be addressed using a variety of methods and especially omics approaches. 
Host susceptibility, drought stress, prevalence of toxigenic strains of A. flavus, insect damage, and cropping system contribute to aflatoxin contamination at harvest (Mehl et al. 2012; Widstrom 1979). Like other ear rot fungi, A. flavus readily gains access and easily invades kernels that have been damaged by insect pests (Marsh and Payne 1984; Parsons and Munkvold 2012; Payne 1998), which leads to more severe contamination compared with invasion through silk channels (Payne 1998). In addition, the timing of harvest also influences contamination, with the fungus being active in aflatoxin synthesis when kernel moisture rises above $13 \%$ (Anonymous 2003; Payne et al. 1988). As such, late harvesting of maize generally results in an increase in aflatoxin contamination (Widstrom 1996). Aflatoxin production can continue postharvest (Giorni et al. 2009b; Sanchis and Magan 2004) if the grain is inadequately dried before storage or if conducive conditions prevail in storage (Villers 2014).

Omics of A. flavus-maize interaction. Omics tools can contribute significantly in understanding the A. flavus-maize interaction and thereby facilitate mitigation of aflatoxin contamination (Bhatnagar 2012; Bhatnagar et al. 2018). Progress has been made in understanding the genomic makeup of A. flavus. Further, proteomics has been applied to study resistance of host genotypes to invasion by A. flavus (Fountain et al. 2018; Tiwari and Shankar 2018). While information on production of aflatoxin and other secondary metabolites by A. flavus is reasonably extensive, application of metabolomics as a tool to understand A. flavus-maize interaction is relatively new (Cary et al. 2018). Here, we briefly discuss the use of functional genomic tools in examining the effects of ecological factors on the development of A. flavus and the interactions between the fungus and maize and how this information could impact the management of aflatoxin contamination.

A. flavus can develop on living plants and on decaying tissues (Payne 1998) and colonization of maize kernels has been studied in depth with respect to the localization, morphology and transcriptional profiles for both the host and the fungus (Dolezal et al. 2014). Secondary metabolism in A. flavus is strongly influenced by ecological conditions and a higher expression of aflatoxin biosynthetic cluster genes during growth of the fungus in living kernels, compared with saprobic growth, has been reported (Reverberi et al. 2013). Although ethylene production in living infected seeds is reported to suppress aflatoxin production, it does enhance colonization of infected seed by A. flavus (Wang et al. 2017).

Several genes within the aflatoxin cluster are modulated by both temperature and $\mathrm{a}_{\mathrm{w}}$, while only $\mathrm{a}_{\mathrm{w}}$ affects the CPA biosynthetic genes (Medina et al. 2017a). However, Bernaldez et al. (2017) note that even if these environmental parameters and their interaction affect fungal growth and aflatoxin production, toxin production is not always consistent with aflatoxin biosynthetic gene expression. Thus, expression of the pathway transcriptional activator, aflR, alone is not a suitable tool to predict the degree of contamination. Studies have been conducted to predict the effect of climate change factors (i.e., elevated $\mathrm{CO}_{2}$, temperature increase, and drought stress) on A. flavus growth, aflatoxin production, and aflR gene expression. Results from these studies show that fungal growth is affected by a three-way interaction between temperature, $\mathrm{a}_{\mathrm{w}}$, and elevated $\mathrm{CO}_{2}$, with relevant changes occurring in the overall secondary metabolism with a significant increase in aflatoxin contamination (Magan and Medina 2016; Medina et al. 2017b). Further, acclimatization of A. flavus to these climate change factors may result in increased disease and perhaps aflatoxin contamination in important cereal crops.

Models for predicting risk of aflatoxin contamination. Modeling to predict the result of the complex interaction between host crops, the fungus and the environment, especially for mycotoxin producing fungi, has received considerable attention in recent years (Battilani et al. 2013; Camardo Leggieri et al. 2013). Given that environmental conditions are crucial for A. flavus, weather data have

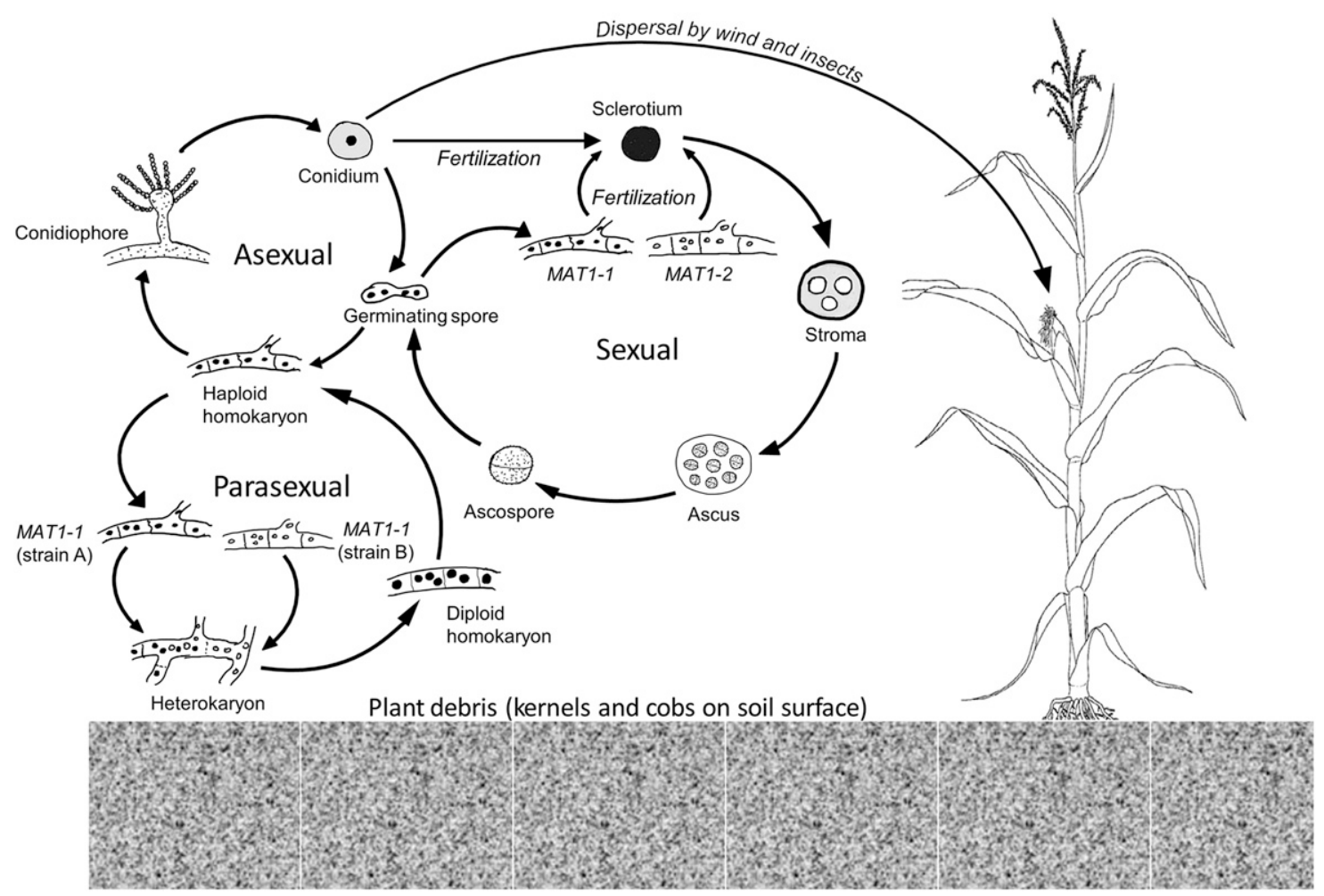

FIGURE 2

Schematic illustration of the life cycle of Aspergillus flavus based on the growth and reproduction of the fungus and infection in maize. While parasexual reproduction has been demonstrated in the laboratory, unequivocal evidence for its occurrence and role under field conditions is still lacking. 
been the main input for these predictions (Battilani et al. 2013). Empirical modeling approaches have been applied to predict the risk of contamination in Australia and Europe. For example, temperature and soil moisture during the maize grain filling period are input data for generating an aflatoxin risk index (ARI) to predict aflatoxin contamination in Australia based on an adaptation of an empirical model that was previously developed for peanut (Chauhan et al. 2008). Similarly, an aridity index that is an input for a logistic regression function used to estimate the probability of $\mathrm{AFB}_{1}$ contamination was computed using temperature, relative humidity and rain records in Italy (Battilani et al. 2008). Validation of the model by Battilani et al. (2008) resulted in correct prediction rates ranging from 60 to $70 \%$, indicating good model performance. While useful, empirical models are not easily transferable to other geographic areas and they need to be recalibrated using local conditions before use.

A more versatile mechanistic model based on the infection cycle of A. flavus and its interaction with maize has also been developed to predict the risk of aflatoxin contamination (Battilani et al. 2013). The model, known as AFLA-maize, works on a daily time-step and the risk is computed daily throughout the growing season. The model output is an index (AFI) that summarizes the probability to exceed the European Union legal limit of $5 \mu \mathrm{g}$ of aflatoxin $\mathrm{B}_{1}$ per $\mathrm{kg}$ of unprocessed maize (European Commission 2010). The model has also been validated using data from different geographical areas resulting in a correct classification rate of $70 \%$, which is indicative of good performance in predicting the risk of aflatoxin contamination. Although meteorological data collected during the maize growing season are the most commonly used for modeling the risk of contamination, historical (collected in the past) and future (predicted) data can also be used as inputs in predictive models. In this case, past and future scenarios are the generated outputs, respectively, and these are usually presented as risk maps, a userfriendly data summary where the spatial gradient of the risk is displayed (Battilani and Logrieco 2014; Battilani et al. 2006). A combination of environmental data and geo-referenced locations of aflatoxin occurrence has been proposed to generate probability maps of the distribution of aflatoxins in Africa (Masuoka et al. 2010).

There have been questions on the practical applications of models developed to predict the risk of aflatoxin contamination. These concerns arise from the fact that aflatoxin mitigation depends on preventive actions while operational decisions throughout the growing season must be taken in advance. Nevertheless, there is a general consensus that these models still play a crucial role in the overall decision management of aflatoxins (Battilani and Camardo Leggieri
2015). For example, using actual data, early harvest can be recommended when the risk of aflatoxin contamination is high. However, when the risk of contamination is low, harvesting can be delayed allowing kernel moisture to decrease which subsequently reduces the costs associated with drying grain after harvest. Secondly, the logistics of harvesting can be better organized regarding the switch of contaminated grain to nonfood/feed use based on model predictions. Thirdly, pre-season decisions can be informed by risk maps generated using historical data input, with more careful maize management in high risk areas. Finally, the impact of climate change can be predicted using future meteorological data as input to inform policy on opportunities and options to manage aflatoxin in a changing world (Battilani et al. 2016a). Growers, extension service agents, and stakeholders working along the maize value chain can also be supported by model outputs based on past and actual data where climate change scenarios are crucial for strategic actions and communication. An interesting example of the latter comes from research supported by the European Food Safety Authority (EFSA) on the future risk of aflatoxin contamination in Europe. Based on a modeling approach, aflatoxin contamination in maize, within the next 100 years, is predicted to become a food safety issue in Europe, especially in the $+2^{\circ} \mathrm{C}$ most probable scenario (Battilani et al. 2016b). These modeling efforts thus represent a supporting tool for policy makers to reinforce aflatoxin management and to prevent possible human and animal exposure.

\section{PREHARVEST AND POSTHARVEST MANAGEMENT OF AFLATOXINS}

Preharvest strategies. Several strategies can be implemented at different stages of crop growth during the growing season to prevent or minimize the risk of aflatoxin contamination (Fig. 3). These strategies offer a key initial step in mitigating contamination in the field that can influence subsequent aflatoxin levels once the produce is out of the field. Comprehensive reviews of these strategies have been presented elsewhere (Bhatnagar-Mathur et al. 2015; Torres et al. 2014) and here we briefly summarize key aspects. Biological control, host resistance, plant density, and good agricultural practices are some of the strategies that are used to prevent or minimize preharvest contamination. While, specific biocontrol agents such as yeasts and bacteria have been demonstrated to be effective in inhibiting accumulation of aflatoxin under controlled conditions (Dorner 2004; Palumbo et al. 2006), application of competitive atoxigenic strains of A. flavus is the most successful to date in controlling aflatoxin contamination in crops prior to

\section{FIGURE 3}

Relative importance of specific agronomic practices that can be implemented during the growing season to minimize the risk of aflatoxin contamination prior to crop harvest.

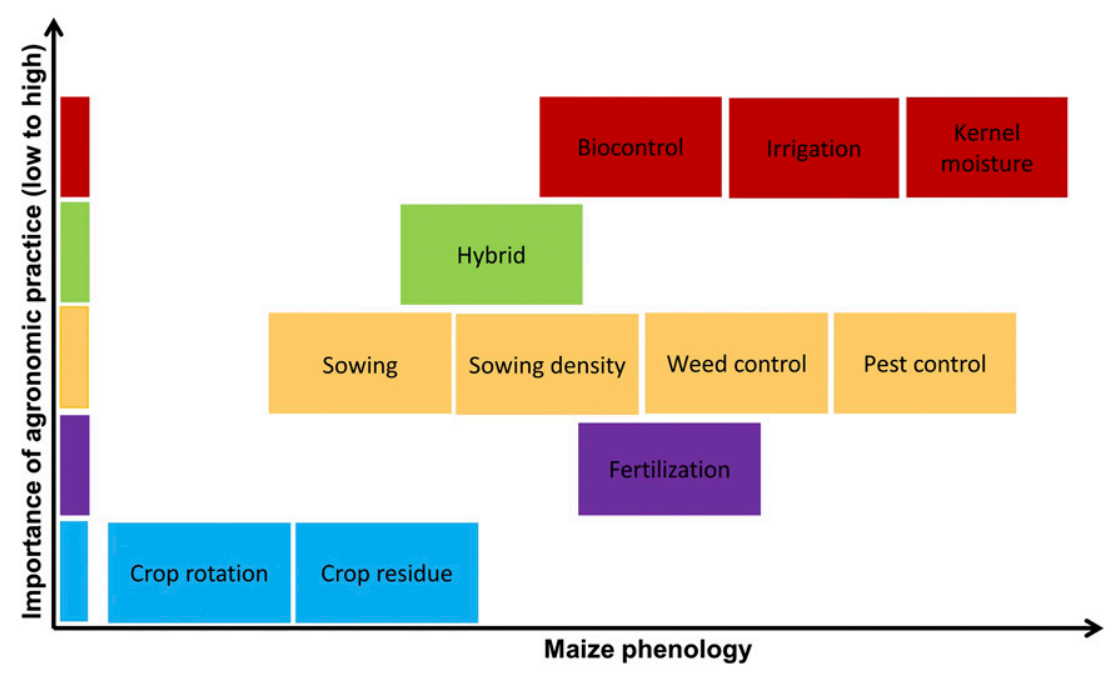


harvest. Afla-Guard and AF36 are two commercial products based on formulations of a single atoxigenic strain of A. flavus in the United States (Dorner 2004). Afla-Guard is registered for use on corn and peanuts, while AF36 is registered for use in almonds, cotton, maize, and pistachio. Aflasafe is a commercial product that is based on a mixture of four atoxigenic strains for use in Africa. Indeed, several Aflasafe products, each with a different set of four atoxigenic strains native for a specific country where the product is deployed, are now available in Africa (Atehnkeng et al. 2016; Ayalew et al. 2017; Bandyopadhyay et al. 2016). In addition, the commercial biocontrol product $\mathrm{AF}-\mathrm{X} 1$ based on the atoxigenic A. flavus strain MUCL54911 is currently under registration for use in maize in Italy (Mauro et al. 2018). Biological control of aflatoxin contamination is based on the premise that atoxigenic strains will displace naturally occurring toxigenic strains from infection sites when high densities of the atoxigenic strains are applied to the soil. Consistent reductions in aflatoxin contamination ranging from 67 to 99\% due to atoxigenic strains have been reported (Alaniz Zanon et al. 2013; Atehnkeng et al. 2014; Bandyopadhyay et al. 2016; Dorner 2009; Mauro et al. 2018).

While there has been considerable progress in identifying host genes for preventing aflatoxin contamination in several crops, progress has been slow and there are no commercially acceptable aflatoxin resistant cultivars (Fountain et al. 2015; Warburton and Williams 2014). Further, variation in aflatoxin contamination is commonly observed in the field even when different hybrids are grown in comparable conditions (Hawkins et al. 2008; Kebede et al. 2012). Crop rotation, pesticide application, soil amendment, and moisture management are some of the good agricultural practices that can be implemented to reduce the incidence of contamination in the field. Rotation works to reduce the build-up of high densities of A. flavus or A. parasiticus in soil and thus reduces the risk of infection and subsequent contamination (Ortiz et al. 2011). However, the impact of rotation on aflatoxin is minimal in environments where the practice has little impact on densities of Aspergillus in the soil (CAC-Codex Alimentarius Commission 2004). Use of pesticides to control growth of mold to reduce aflatoxin contamination has produced mixed results (Kabak et al. 2006). However, use of pesticides to control insect damage during the plant growth may reduce the risk of fungal invasion and aflatoxin contamination, even though reductions may not be significant relative to the legal limits (Abbas et al. 2017; European Commission 1999; Payne 1998). A recent study showed that a maize hybrid expressing a very high degree of transgenic insect protection resulted in low levels of aflatoxin compared with the control, even though differences in the levels of contamination were not statistically significant (Weaver et al. 2017). Amending soil with calcium and manure has been reported to reduce aflatoxin contamination in peanut by up to $90 \%$ (Waliyar et al. 2008) by thickening cell walls and accelerating pod filling and promoting growth of microbial antagonists in soil, respectively (Hell and Mutegi 2011). Drought stress during silking in maize or pod-filling in peanut is considered one of the most important factors that influence aflatoxin contamination. Prolonged moisture stress and soil temperatures of $>22^{\circ} \mathrm{C}$ during this period enhances aflatoxin contamination (Horn 2005). Thus, irrigation to reduce moisture stress during this period is recommended but the practice is not practical in areas with limited water resources. In summary, biological control and moisture management have the greatest impact on reduction of aflatoxin contamination, while crop rotation and residue management have the least impact (Fig. 3).

Harvest and postharvest strategies. Aflatoxins are highly stable secondary metabolites and thus, grain infected by toxigenic strains and/or contaminated preharvest are still at risk during transport, processing, handling, and in storage if environmental conditions favor growth of the fungus (Udomkun et al. 2017). Biological control during preharvest has been reported to be beneficial in postharvest control of aflatoxin contamination (Bandyopadhyay et al. 2016). Given the ability of A. flavus to produce aflatoxins when kernel moisture goes below $28 \%$, time of harvesting should be planned accordingly, while taking into account growers needs to limit drying costs. Kernel moisture below $14 \%$ during storage and moderate temperature and dry environments need to be maintained to limit contamination. Logistics of harvest, drying, and storage systems must be organized to avoid any increase in contamination. In cases where humidity in storage is above the suggested level, addition of $\mathrm{CO}_{2}$ at 25 to $50 \%$ of air content can reduce fungal activity (Giorni et al. 2008). Storage insect pests that can result in quantitative losses during maize storage have also been linked to aflatoxin contamination especially in Africa. Thus, metal silo and Purdue Improved Crop Storage (PICS) bags have been recommended to protect against losses and reduction in aflatoxin contamination (Baoua et al. 2014). Cleaning and/sorting of grain prior to storage can further enhance the benefits of proper storage techniques. For example, removal of fine material (approximately $10 \%$ by weight) in maize has been shown to reduce aflatoxin levels by $84 \%$, with removal of smaller kernels and kernel pieces further reducing aflatoxin levels by 1.8 and $9.4 \%$, respectively ( $\mathrm{Hu}$ et al. 2017). Thus, more accurate grain sorting approaches such as multispectral kernel sorting have been explored with good sensitivity and specificity rates in identifying kernels with aflatoxin levels of $>10 \mathrm{ppb}$ (Stasiewicz et al. 2017). Other technologies such as irradiation, ozone fumigation and treatment of grain in storage with essential oils (Tatsadjieu et al. 2010) are also under consideration for a more complete and integrated solution for postharvest mitigation of aflatoxin contamination.

\section{BIOLOGICAL CONTROL OF AFLATOXIN CONTAMINATION, BIOLOGY, AND DIVERSITY OF A. FLAVUS}

Mechanism(s) of biological control of aflatoxin contamination. Application of atoxigenic strains of A. flavus prior to flowering has been very instrumental in reducing aflatoxin contamination in several crops. This technology, first applied in the United States (Cotty 1990; Dorner and Lamb 2006) and in recent years in Africa (Atehnkeng et al. 2016; Bandyopadhyay et al. 2016) and Europe (Mauro et al. 2018), offers the greatest potential to control aflatoxin preharvest and in storage. Atoxigenic strains in biocontrol formulations are abundant in the year of application but decline thereafter. Thus, these strains are reapplied annually for sustained reduction in aflatoxin contamination. Although it is widely accepted that reduction in aflatoxin contamination through biological control is due to the displacement of toxigenic by atoxigenic strains through founder effects, a strategy commonly referred to as competitive exclusion for space and nutrients (Cotty and Bayman 1993; Mehl et al. 2012), the actual mechanism(s) that results in this reduction is not fully understood (Ehrlich et al. 2015). The need to establish the stability of atoxigenic strains in preventing contamination and decrease the frequency of reapplication has renewed efforts to further investigate the mechanistic basis of biological control of aflatoxin contamination.

Damann (2015) provides a comprehensive review of possible mechanisms of biological control based on experimental studies and suggests touch inhibition (Huang et al. 2011) as the primary mechanism of biological control. Essentially, touch inhibition is a form of intraspecific aflatoxin inhibition requiring growth of the competing strains together during the infection process in such a way that hyphae physically interact or touch and this acts as the trigger to prevent induction of aflatoxin synthesis (Huang et al. 2011). Damann (2015) concludes that application of an atoxigenic strain that is an effective saprobic competitor and utilizes touch inhibition when interacting with an invading toxigenic strain in the infection court may result in sustainable biological control and possibly reduced the 
frequency of necessary applications in the field. However, it is unclear how knowledge of the mechanism of touch inhibition can be specifically utilized to enhance the efficacy of biological control in the field. Further, the specificity of touch inhibition between interacting hyphae has yet to be established and the signaling pathway that down regulates the synthesis of aflatoxin is unknown. Nonetheless, a possible working hypothesis could be that touch inhibition is mediated by a ligand on the surface of an atoxigenic strain that interacts or fails to interact with another ligand on the surface of a toxigenic strain. If a ligand could be recognized, cloned and introduced into a plant host, it potentially could confer 'recognition' by the invading toxigenic strain to prevent or minimize induction of the signaling pathway responsible for activation of aflatoxin biosynthesis. It is not clear whether the touch inhibition also extends to other secondary metabolites such as cyclopiazonic acid, to establish if the touch inhibition phenomenon implicates a more 'global' regulation of secondary metabolites beyond aflatoxins.

Biology and diversity of $\boldsymbol{A}$. flavus. While clonality, i.e., asexual reproduction, is predominant in A. flavus populations, infrequent sexual reproduction generates new genetic variation and maintains aflatoxin production, thereby exacerbating aflatoxin contamination in crop produce (Olarte et al. 2012). Extensive laboratory and field experiments have demonstrated that aflatoxin production is highly heritable, which translates to aflatoxin production being maintained over several generations (Horn et al. 2016; Olarte et al. 2012). Aflatoxin production is a polygenic trait and several genes not involved directly in aflatoxin biosynthesis are influenced by environmental cues and changes (Price et al. 2005). For example, elevated temperature and water stress conditions significantly promote expression of aflatoxin biosynthetic genes increasing aflatoxin production (Medina et al. 2014; Wu et al. 2011). Other environmental factors, such as nitrogen and carbon, interact with promoters of aflatoxin biosynthetic genes to support or repress transcription (Price et al. 2005). This ongoing genotype by environment interaction makes it challenging to manage and predict outbreaks of aflatoxin.

Sexual reproduction in $A$. flavus. The discovery of sexual reproduction in $A$. flavus and allied species has provided new perspectives on how the genetics and genomic composition of these species can influence their potential to produce aflatoxin (Horn et al. 2009a, b, 2011). Specifically, Ramirez-Prado et al. (2008) discovered and reported that $A$. flavus has a bipolar mating system and individual strains have only one of two possible mating types, i.e., either MAT11 or MAT1-2. Each strain is hermaphroditic with a sclerotium functioning as the female and a conidium serving as the male during sexual reproduction (Horn et al. 2016). Sclerotia are transformed into stromata during sexual reproduction, a phenomenon that has also been reported for other sclerotium-forming members of Aspergillus section Nigri (Horn et al. 2013; Olarte et al. 2015a). Hermaphroditism enables reciprocal crosses between sclerotia and conidia, but invariably only one sclerotia-conidia combination is highly fertile while the reciprocal combination exhibits low fertility (Horn et al. 2016). For example, a cross is highly fertile when the A. flavus sclerotia of the MAT1-1 parent strain is mated with conidia of the MAT1-2 parent but of low fertility when the A. flavus conidia of the MAT1-1 parent strain is mated with sclerotia of the MAT1-2 parent. Results from laboratory and field experiments showed that (i) conidia or hyphal fragments can fertilize single-strain sclerotia, (ii) the sclerotial parent drives differences in the degree of sexual fertility, and (iii) all progeny strains show maternal inheritance of mitochondria from the sclerotial parent (Horn et al. 2016). The relative abundance of sclerotial and conidial vegetative propagules in fields could have significant implications for biological control, which releases a high density of conidia of a single A. flavus strain (Cotty 1990; Dorner and Lamb 2006) or multiple strains (Bandyopadhyay et al. 2016). When clonality predominates in populations fewer isolates go through sexual reproduction; vegetative or asexual propagation predominates, and aflatoxin levels are mostly determined by a few genotypes (i.e., vegetative compatibility groups or VCGs) that can better grow vegetatively and produce more sclerotia and conidia.

The importance of sexual reproduction in maintaining aflatoxin production is evidenced by several species in Aspergillus section Flavi (Carbone et al. 2007b; Horn et al. 2009a, b, 2011; Olarte et al. $2015 b$ ). In the absence of sex, the ability to produce diversity in aflatoxin chemotypes is diminished (Moore et al. 2013). For example, A. caelatus and A. tamarii, which are predominantly asexual, have mating type frequency distributions that are skewed to one mating type, and are nonaflatoxigenic (Moore 2010). Aflatoxin-producing species such as A. flavus may become more nonaflatoxigenic if (i) strains that do not make aflatoxin make more spores, (ii) specific environmental conditions are present that are nonconducive for aflatoxin production, and (iii) sexual reproduction is too infrequent to spread and maintain the determinants of aflatoxigenicity in populations, or a combination of any of the above processes. It is hypothesized that current biological control strategies using EPA approved A. flavus nonaflatoxigenic strains, AF36 and Afla-Guard, work because they artificially and transiently increase the frequency of one genotype, such that populations are predominantly of a single nonaflatoxigenic mating type, precluding sexual reproduction. However, since this approach does not work in concert with the reproductive and mating biology of the fungus, reduction in aflatoxigenicity is not sustainable, and biocontrol products typically need reapplication every growing season (Abbas et al. 2017).

Population genetics of $A$. flavus and biological control of aflatoxin. Current research is elucidating the underlying population genetic and evolutionary processes that occur when biocontrol strains are applied to fields. The widespread sampling of field populations has revealed the existence of two distinct $A$. flavus evolutionary lineages, designated as lineage IB and IC (Geiser et al. 2000; Moore et al. 2009, 2013). Lineage IB strains are frequently nonaflatoxigenic, whereas lineage IC strains vary widely in their ability to make aflatoxins, ranging from those that are nonaflatoxigenic (e.g., AF36) to those that are potent producers of aflatoxins (Moore et al. 2017). While both Afla-Guard and AF36 are nonaflatoxigenic and effective in reducing aflatoxin levels (Abbas et al. 2017), they belong to different evolutionary lineages. Afla-Guard is a lineage IB strain and missing the entire aflatoxin gene cluster (Moore et al. 2009); AF36 is a lineage IC strain with a full gene cluster, and except for a single nonsense mutation in $p k s A$ (=aflC; polyketide synthase gene) (Ehrlich and Cotty 2004), is closely related to other aflatoxin-producing strains in lineage IC (Abbas et al. 2011). The recurrent sampling of both lineages IB and IC in field populations worldwide indicates their importance in the ecology and evolution of this fungus (Carbone et al. 2007a; Moore et al. 2017). Although both lineages are present in fields, their frequencies can be different (Moore et al. 2013). A lineage skew may arise from (i) differential lineage-specific sexual recombination and fertility, (ii) differential lineage-specific spore production, or (iii) differential responses of lineages to changing environmental factors, or latitude gradients. While VCGs in A. flavus lineages have remained stable for more than 50,000 years (Grubisha and Cotty 2010), ongoing genetic exchange and recombination has shuffled determinants of vegetative incompatibility within lineages giving rise to new genotypes with different levels of aflatoxigenicity (Moore et al. 2013). Lineage-specific mating and recombination would maintain the nonaflatoxigenicity typically observed in lineage IB and the aflatoxigenic trait commonly observed in lineage IC. This implies that any sustained reduction in aflatoxin levels would need to impact populations at the lineage level as aflatoxigenicity or nonaflatoxigenicity is highly heritable (Olarte et al. 2012), which translates to field populations consistently harboring a mix of both toxigenic and atoxigenic strains in each generation.

Mating experiments in the laboratory and field indicate that both lineages IB and IC have varying levels of intra- and interfertility 
(Horn et al. 2016; Olarte et al. 2012). We know that A. flavus field populations have the potential for sexual reproduction, but we need a better estimate of the population recombination rates. The timing and frequency of recombination could inform new management strategies. For example, if recombination rates are low, then a control method to drive certain beneficial genetic backgrounds that reduce aflatoxin concentrations in the population may not be effective, and highly fertile biocontrol strains need to be applied in the field to increase sexual reproduction. Longitudinal population genetic studies in maize fields indicate evolution of new A. flavus genotypes one year after application of biocontrol agents (I. Carbone, unpublished data). Moreover, there are lineage-specific differences in recombination rates, which may be associated with variation in levels of fertility; for example, previous work showed that the most fertile A. flavus strains are from lineage IC (Horn et al. 2009b, 2016). Evidence from population genomics analysis indicates that the population genetic structure of these fungi can be altered after a single growing season and in a lineage-specific fashion (I. Carbone, unpublished data). Current efforts are underway to create a genetic linkage map for A. flavus that will provide us with recombination rate estimates in crosses of low and high fertility and will inform how the degree of sexual fertility impacts the amount of introgression and aflatoxin production. While much is known about A. flavus biology and evolution, the underlying mechanisms that result in lower aflatoxin levels have not been elucidated, nor has an approach been proposed that takes advantage of insights from population biology to mitigate aflatoxin contamination in maize and other crops.

\section{CONVENTIONAL AND MOLECULAR MARKER- ASSISTED BREEDING FOR AFLATOXIN RESISTANCE}

Conventional breeding has the potential to increase genetic resistance to aflatoxin accumulation while simultaneously complementing efforts to unravel the molecular basis of maize defenses against $A$. flavus. However, developing maize lines with resistance to A. flavus infection and aflatoxin accumulation has proven challenging. In the United States, public breeding efforts to improve resistance to aflatoxin accumulation in maize date back to the 1970s (Williams et al. 2008). Although some aflatoxin-resistant maize lines have been developed through conventional breeding (recently reviewed by Williams et al. 2014), they also generally display undesirable traits that limit their utility in hybrid development. To accelerate the deployment of commercially viable resistance to aflatoxin, various sources of genetic resistance have been explored by the maize breeding community to identify novel traits. For example, historic maize land races actively cultivated in Mexico, near the center of origin of maize, are a promising potential source of resistance. An evaluation of diverse maize landraces from Mexico for resistance and susceptibility to aflatoxin accumulation identified potentially important sources of aflatoxin resistance (Ortega-Beltran et al. 2014). Tropical inbred lines represent another potential source of genetic resistance. Resistance to aflatoxin accumulation was identified in numerous elite inbred lines developed by the International Institute of Tropical Agriculture (IITA) in African environments (Brown et al. 2001) and in field evaluations in the United States (Brown et al. 2016). However, despite consistent progress in identifying and introgressing genetic resistance, no commercial hybrids are yet available with resistance to aflatoxin accumulation, most likely due to linkage drag from undesirable agronomic traits (Warburton and Williams 2014).

Due to difficulties associated with developing aflatoxin-resistant maize lines, developing molecular markers has become a priority for many breeding programs focused on aflatoxin resistance. Thus far, few reliable DNA-based markers, derived from polymorphisms such as indels, SSRs, or SNPs, have been reported in the literature for aflatoxin resistance in maize. Mississippi Marker 1 (MpM1) was identified from the integration of differential gene expression data (derived from resistant versus susceptible maize lines) and the physical location of known QTL underlying aflatoxin resistance (Mylroie et al. 2013). However, the QTL detected by MpM1 may not convey enough phenotypic variation to be of immediate use in commercial breeding programs. The future development of robust molecular markers would be dramatically accelerated by the identification of specific genes associated with resistance. To this end, proteomics-based approaches identified three general categories of resistance-associated proteins (RAPs) in maize kernels: storage proteins, stress-responsive proteins, and antifungal proteins (Chen et al. 2007, 2012). Subsequently, the involvement of two RAPs in resistance to aflatoxin accumulation was confirmed (Chen et al. 2010). New approaches, such as genome-wide association studies (GWAS), hold distinct promise in identifying novel markers for aflatoxin resistance. A novel association mapping panel that incorporates aflatoxin-resistant germplasm has identified at least 21 genetic regions of maize associated with aflatoxin resistance (Warburton et al. 2013), and a large number of SNPs associated with aflatoxin resistance (Warburton et al. 2015). From this information, the future potential for developing new molecular markers is promising.

\section{TRANSGENIC APPROACHES TO ACHIEVE AFLATOXIN RESISTANCE IN MAIZE}

Resistance in maize to A. flavus and aflatoxin contamination is multigenic, and subject to environmental influences, and thus, difficult to manipulate during classical breeding procedures to create commercial hybrids. The saprobic life style of the soilinhabiting A. flavus presents additional challenges in development of resistance to this weakly aggressive opportunistic pathogen. The fungus does not abide by the typical gene for gene resistance mechanisms observed in many host-pathogen interactions. While efforts have been made to breed maize hybrids for enhanced resistance to aflatoxin contamination (Okoth et al. 2017; Warburton and Williams 2014), the process is time consuming and all resistant lines to date contain tropical germplasm in their backgrounds resulting in less than desirable agronomic traits (Warburton and Williams 2014). Molecular breeding through transgenic approaches provides a less time consuming, alternative or complimentary approach to improve control of A. flavus infection and aflatoxin contamination in maize (Cary et al. 2011). Transgenic approaches that impart increased resistance to A. flavus and aflatoxin contamination in maize have been reported on (i) the development of transgenic maize overexpressing antifungal genes encoding resistance-associated proteins or peptides, both native and from other sources (Rajasekaran et al. 2018; Schubert et al. 2015); and (ii) use of RNA interference-based methods targeting genes critical to A. flavus growth and aflatoxin production (Majumdar et al. 2017a).

Enhanced aflatoxin resistance through incorporation of antifungal genes. Though not directly targeting A. flavus, transgenic Bt maize expressing one or more crystal (Cry) genes encoding insecticidal proteins from Bacillus thuringiensis have been analyzed with respect to their ability to reduce aflatoxin contamination (Ostrý et al. 2015; Weaver et al. 2017). Both studies examined data from a number of independent reports on the effect of Bt maize on aflatoxin levels and both concluded that results were highly variable, probably due to differences in sampling years, corn genotypes, and environmental factors. It is unlikely that transgenic approaches targeting insect damage alone in maize will provide durable and significant control of aflatoxin contamination since $A$. flavus can also invade the maize ear via silk channels (Marsh and Payne 1984).

In order to achieve the goal of efficacious control of aflatoxin contamination in maize via transgenic approaches, it is incumbent that genes encoding RAPs, regulatory genes and signaling pathway 
components be identified and assessed for their level of contribution to seed-based resistance. To this end, numerous studies utilizing classical biochemical and molecular techniques (Chen et al. 2001; Moore et al. 2004) and next generation-omics technologies such as 2D comparative proteomics (Chen et al. 2012; Xie et al. 2015), genomics (Farfan et al. 2015; Warburton et al. 2015), transcriptomics (Shu et al. 2015; Shu et al. 2017), and interactomics (Musungu et al. 2016) have identified a plethora of candidate RAP genes and proteins from maize. While this may be good for the development of molecular markers for use in marker-assisted breeding strategies, the large number of candidate genes arising from these types of studies cannot realistically be screened in toto for subsequent introduction and overexpression in maize. Narrowing down the selection of RAP genes, both native and from other sources, for transformation into maize can include the following: (i) reports of resistance genes or proteins from other plants that inhibit growth of A. flavus (Prasad et al. 2013; Sundaresha et al. 2010); (ii) validation of maize genes or proteins identified by transcriptomic or proteomic analyses of resistant and susceptible maize lines (Chen et al. 2016, 2010); and (iii) development of synthetic genes encoding antifungal peptides (Cary et al. 2000; Rajasekaran et al. 2009, 2018). To assist research on maize genes and proteins that may serve as candidates for control of $A$. flavus infection and aflatoxin contamination, the Corn Fungal Resistance Associated Sequences Database (CFRAS-DB; http://www.agbase.msstate.edu/cgi-bin/information/ Maize.pl) has been developed and compiles all genetic and protein sequences and QTL regions reported to be associated with $A$. flavus or aflatoxin resistance in maize (Kelley et al. 2010).

Despite all of the genetic and proteomic information gathered on candidate RAPs, both native and from other sources, for resistance to A. flavus and aflatoxin contamination in maize, only two reports have been published on transgenic expression of RAPs in maize for this purpose. The reticence to introduce and overexpress native or foreign RAP genes in maize may largely be due to the identification of maize lines with natural resistance that are being used in breeding programs as sources of resistance traits that can be introgressed into agronomically desirable commercial lines. However, as stated above, resistance is multigenic and many of these resistant lines are derived from tropical germplasm with a number of undesirable agronomic traits that will require a considerable amount of time to breed resistance traits into commercially viable lines. Efforts to genetically engineer transgenic lines for resistance to A. flavus growth and aflatoxin contamination can be used to complement and enhance native resistance breeding programs and perhaps shorten the time required to develop maize demonstrating superior resistance. To date, the two reports of transgenic expression of RAPs in maize for control of aflatoxin contamination did not use genes from maize or other plants. Instead, both studies utilized synthetically-derived, small antimicrobial peptides (AMPs) (Rajasekaran et al. 2018; Schubert et al. 2015). Transgenic expression in maize of the spined soldier bug (Podisus maculiventris) 21 amino acid thanatin AMP in a maize Hi-II hybrid variety resulted in an approximate threefold increase in resistance to $A$. flavus infection compared with control lines (Schubert et al. 2015). Unfortunately, levels of aflatoxin production in transgenic lines were not determined. Rajasekaran et al. (2018) demonstrated enhanced resistance in transgenic maize plants expressing a synthetic peptide derived from an AMP described in the Japanese horseshoe crab (Tachypleus tridentatus). Kernels from transgenic Hi-II maize plants transformed with the tachyplesin-1 derived, an 18 amino acid synthetic peptide AGM182, demonstrated up to a $72 \%$ reduction in A. flavus growth and 76 to $98 \%$ reduction in aflatoxin contamination compared with control lines. AGM182 modifications from native tachyplesin include substitution of amino acids to increase hydrophobicity resulting in superior antimicrobial activity and removal of a tryptophan moiety leading to reduced lysis of mammalian erythrocytes.

Enhanced resistance through host-induced gene silencing. RNA interference (RNAi) is a form of host-induced gene silencing.
The molecular machinery required for RNAi is highly conserved in many organisms including plants and fungi and it functions by degrading messenger RNA (mRNA) for specific genes before they are translated into protein (Katoch and Thakur 2013). Important characteristics of RNAi include its systemic nature, heritability, and fairly high level of target specificity. Virtually any gene of interest can be silenced when constructs that produce double stranded, hairpin RNAs (hpRNAs) based on the targeted gene sequence are introduced in a host of interest (Katoch and Thakur 2013; Nunes and Dean 2012). RNAi has been demonstrated in a number of fungi including A. flavus, A. oryzae, and $F$. graminearum (reviewed in Majumdar et al. 2017a) and F. verticillioides (Johnson et al. 2018).

In the context of development of maize for resistance to aflatoxin contamination, RNAi can be used for two purposes. First, as candidate maize resistance genes are identified through transcriptomics or other means, their contribution to overall resistance can be validated by silencing of the target RAP gene using RNAi-based approaches. Subsequent bioassay of transgenic RNAi maize seed for levels of resistance to fungal virulence and toxin production can then be compared with control seed. The utility of RNAi in validation of maize RAP genes identified in proteomic or transcriptomic studies has been reported for PR10 (Chen et al. 2010), trypsin inhibitor (TI) (Chen et al. 2016) and PRms (Majumdar et al. 2017b). This information can then be used to select the most promising RAP genes for use in marker-assisted breeding in maize or for introduction into maize or other susceptible crops like cotton and peanut (that do not possess native resistance) to enhance resistance to aflatoxin contamination. Secondly, RNAi-based binary vectors can be engineered and introduced into maize that target genes of the invading A. flavus for silencing that are critical for colonization and aflatoxin production.

There are several examples in the literature on the use of RNAi to suppress A. flavus growth and aflatoxin production in maize and peanut. Masanga et al. (2015) examined the effect that transgenic maize, constitutively expressing hpRNAs targeting the aflatoxin pathway regulatory gene, aflR, had on production of aflatoxin. Following in planta infection of transgenic and control plants with an aflatoxigenic $A$. flavus, kernel samples were assayed for $a f l R$ expression using semiquantitative RT-PCR. The authors noted reduced levels of aflR expression in transgenics compared with control plants and a 14-fold reduction in $\mathrm{AFB}_{1}$ content as determined by ELISA. The authors also observed that transgenic plants expressing the RNAi cassette were severely stunted and had reduced kernel placement possibly due to silencing of 'off target' genes. Thakare et al. (2017) described significant reduction in aflatoxin levels in transgenic maize transformed with an RNAi cassette affording seed-specific expression of hpRNAs targeting the aflC gene. RT-PCR confirmed expression of the aflC-RNAi cassette in transgenic seed and qRT-PCR also showed significant down-regulation of aflC expression in RNAi lines compared with controls. No aflatoxin was detected by quantitative densitometry of thin layer chromatographs (limit of detection $\leq 93 \mathrm{ppb}$ ) of extracts from in planta infected transgenic seed while controls showed extremely high levels of aflatoxin. RNA sequence (RNA-seq) analysis of transcripts from transgenic and nontransgenic controls showed no significant differences in levels of gene expression indicating that there were no 'off target' effects due to expression of the aflC-RNAi cassette. Gilbert et al. (2018) demonstrated silencing of the A. flavus $\alpha$-amylase (amyl) gene during in situ infection of individual kernels collected from ears of maize plants harboring a constitutively-expressed amy-RNAi construct. They observed a significant reduction in expression of amyl in the amyl-RNAi lines (vs. negative control) by qRT-PCR. This correlated with a significant reduction of fungal growth as determined by fluorescence detected from the GFP-expressing A. flavus strain used to infect the kernels. Reduced amylase expression also coincided with drastically reduced $\mathrm{AFB}_{1}$ accumulation in the amy-RNAi maize seed compared with control seed. One of the amyl-RNAi lines showed a reduction in $\mathrm{AFB}_{1}$ of approximately 100-fold compared with a transformed control line. 
They suggest that the observed reduction in fungal growth and aflatoxin production are likely due to the inability of the fungus to hydrolyze starch for use as a carbon source during seed infection, as starch degradation products such as glucose, maltose, and maltotriose are known to be important for growth, and serve as inducers of aflatoxin biosynthesis in maize (Fakhoury and Woloshuk 1999).

With respect to use of RNAi approaches to control aflatoxin contamination in peanut, Arias et al. (2015) examined the ability of transgenic peanut expressing a hpRNA that targeted a total of five genes (aflR, aflatoxin gene cluster transcriptional activator; aflS, aflatoxin gene cluster transcriptional coactivator; $a f l C$, aflatoxin polyketide synthase; aflep, a putative aflatoxin efflux pump; and pes 1, a NRPS responsible for tolerance to oxidative stress) involved either directly or indirectly in aflatoxin biosynthesis. Using in situ assays of half cotyledons, RNAi-expressing peanut lines had up to $100 \%$ reduction in $\mathrm{AFB}_{1}$ and $\mathrm{AFB}_{2}$ compared with the control. Interestingly, qRT-PCR of mRNA from transgenic cotyledons only detected expression of the hpRNAs in $24 \mathrm{~h}$ immature cotyledons and not at $48 \mathrm{~h}$ and no expression was detected in mature cotyledons at any of the time points. The authors did not present data on levels of expression of the targeted genes in the RNAi and control seed. A subsequent study by Power et al. (2017) using high throughput sequencing of small RNA (sRNA) libraries generated from two of the RNAi peanut lines and a control line identified two sRNAs that matched regions of the hpRNA construct coding for the aflS and aflC genes present only in the RNAi lines. In addition, there were 39 sRNAs that mapped without mismatches to the genome of $A$. flavus and were present only in the transformed RNAi lines. Sharma et al. (2018) developed transgenic peanut lines for control of aflatoxin contamination using an RNAi-based approach or an approach that utilized overexpression of defensin genes from Medicago. Transgenic plants expressing hpRNAs for RNAi-based silencing of the aflatoxin biosynthetic genes aflM and aflP or those overexpressing $M s$ Defl or MtDef4.2 showed significant decreases in $\mathrm{AFB}_{1}$ content in A. flavus infected peanut cotyledons. Aflatoxin $\mathrm{B}_{1}$ levels were reduced from an average of $2,000 \mathrm{ppb}$ in controls to less than $20 \mathrm{ppb}$ (the maximum levels allowed by the U.S. FDA) in the RNAi lines as determined by highly sensitive HPLC detection methods. A strong positive correlation was observed between reduction in aflatoxin levels and aflatoxin biosynthetic gene expression using qRT-PCR.

Continued transcriptomic and interactomic analyses of the maize-A. flavus interaction under varying environmental conditions should reveal even more potential RAP genes for use in development of resistant maize lines and as molecular markers for markerassisted breeding strategies. As improvements are made to the efficiency of gene editing technologies (e.g., CRISPR/Cas9) for the silencing or introduction of RAP genes in maize, these technologies may replace conventional transgenic approaches including RNAi (Gao et al. 2018). However, current reports on the use of transgenic approaches to enhance resistance in maize to A. flavus infection and aflatoxin production appear promising. Most of these reports are based on small-scale laboratory or greenhouse studies. Follow up studies are needed in a field environment over several growing seasons to take into account environmental effects on the durability of observed resistance. Ultimately, large-scale application of transgenic maize for control aflatoxin contamination will most likely depend on the willingness of industry to dedicate resources to the development and commercialization of transgenic maize for resistance to mycotoxigenic fungi, and the willingness of consumer to accept food and feed derived from a 'GMO' crop.

\section{CONCLUSIONS AND POTENTIAL APPLICATION OF CONCEPTS TO OTHER MYCOTOXIN PRODUCING FUNGI}

Contamination of important field and tree nut crops by aflatoxin following infection by $A$. flavus still remains a serious problem worldwide and particularly in developing countries where cereals are the staple crop. There has been considerable progress in understanding the biology of the fungus and how this new information relates to key aspects in the management and control of aflatoxin contamination. The recent use of atoxigenic strains as commercial biocontrol agents to control contamination in the field emphasizes the significant milestone that has been achieved in aflatoxin research in the United States, Africa, and Europe. However, questions associated with the economics and sustainability of this strategy still remain. Current insights in the population biology of $A$. flavus provide an opportunity to harness knowledge on sexual fertility, mating and recombination to develop a platform for designing sustainable biocontrol strategies. Information gathered from-OMICS technologies such as genomics, transcriptomics, and metabolomics will shed additional light on the mechanisms governing the maize-fungus interaction, especially with respect to host resistance mechanisms. Analysis of coexpression networks will identify A. flavus genes and proteins that influence maize resistance mechanisms. As maize resistance genes are identified they can serve as markers for use in marker-assisted breeding strategies while genes critical to the success of A. flavus infection and aflatoxin accumulation can serve as targets of host-induced gene silencing approaches utilizing RNAi. The advent of new genome editing technologies in agriculture could propel a fundamental rethinking of strategies to identify genes underlying responses to A. flavus infection. For example, genes conveying susceptibility to aflatoxin accumulation could be promising targets for inactivation via genome editing. Additionally, mechanisms of resistance to aflatoxin accumulation in other crops could potentially inform genome editing strategies in maize and vice versa. While significant progress has been made in generation of knowledge and its application in developing useful tools for aflatoxin mitigation, there are aspects of the maize-A. flavus pathosystem that still need to be addressed especially with breeding for resistance against aflatoxin contamination. New challenges are emerging, with climate change playing an important role. The wide variability in environmental conditions between and during growing seasons will continue to add uncertainty to expected contamination scenarios at harvest in all geographic areas. Co-occurrence of members of Aspergillus section Flavi with other ear rot fungi is becoming increasingly important and predictions of contamination using reliable models will continue to be a useful tool for all stakeholders of the value chain to support rationale and sustainable preventive and corrective actions.

\section{LITERATURE CITED}

Abbas, H. K., Accinelli, C., and Shier, W. T. 2017. Biological control of aflatoxin contamination in U.S. crops and the use of bioplastic formulations of Aspergillus flavus biocontrol strains to optimize application strategies. J. Agric. Food Chem. 65:7081-7087.

Abbas, H. K., Weaver, M. A., Horn, B. W., Carbone, I., Monacell, J. T., and Shier, W. T. 2011. Selection of Aspergillus flavus isolates for biological control of aflatoxins in corn. Toxin Rev. 30:59-70.

Alaniz Zanon, M. S., Chiotta, M. L., Giaj-Merlera, G., Barros, G., and Chulze, S. 2013. Evaluation of potential biocontrol agent for aflatoxin in Argentinean peanuts. Int. J. Food Microbiol. 162:220-225.

Angle, J. S., Lindgren, R. L., and Gilbert-Effiong, D. 1989. Survival of Aspergillus flavus conidia in soil. Biodet. Res. 2:245.

Anonymous. 2003. Mycotoxins: Risks in Plant, Animal and Human Systems. Council for Agricultural Science and Technology, Ames, IA.

Arias, R. S., Dang, P. M., and Sobolev, V. S. 2015. RNAi-mediated control of aflatoxins in peanut: Method to analyze mycotoxin production and transgene expression in the peanut/Aspergillus pathosystem. J. Vis. Exp. 106:e53398.

Atehnkeng, J., Donner, M., Ojiambo, P. S., Ikotun, B., Augusto, J., Cotty, P. J., and Bandyopadhyay, R. 2016. Environmental distribution and genetic diversity of vegetative compatibility groups determine biocontrol strategies to mitigate aflatoxin contamination of maize by Aspergillus flavus. Microbiol. Biotechnol. 9:75-88.

Atehnkeng, J., Ojiambo, P. S., Cotty, P. J., and Bandyopadhyay, R. 2014. Field efficacy of a mixture of atoxigenic Aspergillus flavus Link: Fr vegetative 
compatibility groups in preventing aflatoxin contamination in maize (Zea mays L.). Biol. Control 72:62-70.

Ayalew, A., Kimanya, M., Matumba, L., Bandyopadhyay, R., Menkir, A., and Cotty, P. 2017. Controlling aflatoxins in maize in Africa: Strategies, challenges and opportunities for improvement. Pages 1-24 in: Achieving Sustainable Cultivation of Maize. Volume 2: Cultivation Techniques, Pest and Disease Control. D. Watson, ed. Burleigh Doods Science Publishing, Cambridge.

Bandyopadhyay, R., Ortega-Beltran, A., Akande, A., Mutegi, C., Atehnkeng, J., Kaptoge, L., Senghor, A. L., Adhikari, B. N., and Cotty, P. J. 2016. Biological control of aflatoxins in Africa: Current status and potential challenges in the face of climate change. World Mycotoxin J. 9:771-789.

Baoua, I. B., Amadou, L., Ousmane, B., Baributsa, D., and Murdock, L. L. 2014. PICS bags for post-harvest storage of maize grain in West Africa J. Stored Prod. Res. 58:20-28.

Battilani, P., Barbano, C., Marin, S., Sanchis, V., Kozakiewicz, Z., and Magan, N. 2006. Mapping of Aspergillus section Nigri in Southern Europe and Israel based on geostatistical analysis. Int. J. Food Microbiol. 111:S72-S82.

Battilani, P., Barbano, C., and Piva, G. 2008. Aflatoxin $\mathrm{B}_{1}$ contamination in maize related to the aridity index in North Italy. World Mycotoxin J. 1: 449-456.

Battilani, P., and Camardo Leggieri, M. 2015. Predictive modelling of aflatoxin contamination to support maize chain management. World Mycotoxin J. 8:161-170.

Battilani, P., Camardo Leggieri, M., Rossi, V., and Giorni, P. 2013. AFLAmaize, a mechanistic model for Aspergillus flavus infection and aflatoxin $\mathrm{B}_{1}$ contamination in maize. Comput. Electron. Agric. 94:38-46.

Battilani, P., Formenti, S., Ramponi, C., and Rossi, V. 2011. Dynamic of water activity in maize hybrids is crucial for fumonisin contamination in kernels. J. Cereal Sci. 54:467-472.

Battilani, P., and Logrieco, A. 2014. Global risk maps for mycotoxins in wheat and maize. Pages 309-326 in: Mycotoxin Reduction in Grain Chains: A Practical Guide. J. Leslie and A. Logrieco, eds. Wiley-Blackwell, Hoboken, NJ.

Battilani, P., Stroka, J., and Magan, N. 2016b. Foreward: Mycotoxins in a changing world. World Mycotoxin J. 9:647-651.

Battilani, P., Toscano, P., Van der Fels-Klerx, H. J., Moretti, A., Camardo Leggieri, M., Brera, C., Rortais, A., Goumperis, T., and Robinson, T. 2016a. Aflatoxin $B_{1}$ contamination in maize in Europe increases due to climate change. Sci. Rep. 6:24328.

Bernaldez, V., Cordoba, J. J., Magan, N., Peromingo, B., and Rodriguez, A. 2017. The influence of ecophysiological factors on growth, aflR gene expression and aflatoxin $\mathrm{B}_{1}$ production by a type strain of Aspergillus flavus. Food Sci. Technol. 83:283-291.

Bhat, R. V., and Krishnamachari, K. A. 1977. Follow-up study of aflatoxic hepatitis in parts of western India. Indian J. Med. Res. 66:55-58.

Bhatnagar, D. 2012. The "omics" approach for solving the pre-harvest aflatoxin contamination problem: understanding the genomics and metabolomics of the fungus and proteomics of the affected corn crop. Pages 192-196 in: Biotechnology Summit 2012. F. Fernández-Luqueño, F. López-Valdez, and S. Lozano-Muñiz, eds. Cinvestav, Mexico.

Bhatnagar, D., Rajasekaran, K., Gilbert, M., Cary, J. W., and Magan, N. 2018. Advances in molecular and genomic research to safeguard food and feed supply from aflatoxin contamination. World Mycotoxin J. 11:47-72.

Bhatnagar-Mathur, P., Sunkara, S., Bhatnagar-Panwar, M., Waliyar, F., and Sharma, K. K. 2015. Biotechnological advances for combating Aspergillus flavus and aflatoxin contamination in crops. Plant Sci. 234:119-132.

Blount, W. P. 1961. Turkey 'X' disease. J. Br. Turk. Fed. 9:55-58.

Brown, R. L., Williams, W. P., Windham, G. L., Menkir, A., and Chen, Z. 2016. Evaluation of African-bred maize germplasm lines for resistance to aflatoxin accumulation. Agronomy (Basel) 6:24.

Brown, R. L., Zhi-Yuan Chen, Z., Menkir, A., Cleveland, T. E., Cardwell, K., Kling, J., and White, D. G. 2001. Resistance to aflatoxin accumulation in kernels of maize inbreds selected for ear rot resistance in West and Central Africa. J. Food Prot. 64:396-400.

CAC-Codex Alimentarius Commission. 2004. Code of practice for the prevention and reduction of aflatoxin contamination in peanuts. CAC/RCP 55.

Camardo Leggieri, M., Van der Fels-Klerx, H. J., and Battilani, P. 2013. Crossvalidation of predictive models for deoxynivalenol in wheat at harvest. World Mycotoxin J. 6:389-397.

Carbone, I., Jakobek, J. L., Ramirez-Prado, J. H., and Horn, B. W. 2007 b. Recombination, balancing selection and adaptive evolution in the aflatoxin gene cluster of Aspergillus parasiticus. Mol. Ecol. 16:4401-4417.

Carbone, I., Ramirez-Prado, J. H., Jakobek, J. L., and Horn, B. W. 2007a. Gene duplication, modularity and adaptation in the evolution of the aflatoxin gene cluster. BMC Evol. Biol. 7:111.

Carvajal-Campos, A., Manizan, A. L., Tadrist, S., Akaki, D. K., Koff-Nevry, R., Moore, G. G., Fapohunda, S. O., Bailly, S., Montet, D., Oswald, I. P., Lorber, S., Brabet, C., and Puel, O. 2017. Aspergillus korhogoensis, a novel aflatoxin producing species from the Côte d'Ivoire. Toxins (Basel) 9:353.
Cary, J. W., Gilbert, M. K., Lebar, M. D., Majumdar, R., and Calvo, A. M. 2018. Aspergillus flavus secondary metabolites: More than just aflatoxins. Food Saf. 6:7-32.

Cary, J. W., Rajasekaran, K., Brown, R. L., Luo, M., Chen, Z. Y., and Bhatnagar, D. 2011. Developing resistance to aflatoxin in maize and cottonseed. Toxins (Basel) 3:678-696.

Cary, J. W., Rajasekaran, K., Jaynes, J. M., and Cleveland, T. E. 2000. Transgenic expression of a gene encoding a synthetic antimicrobial peptide results in inhibition of fungal growth in vitro and in planta. Plant Sci. 154:171-181.

Chauhan, Y. S., Wright, G. C., and Rachaputi, N. C. 2008. Modelling climatic risks of aflatoxin contamination in maize. Aust. J. Exp. Agric. 48:358-366.

Chen, Z.-Y., Brown, R. L., Cleveland, T. E., Damann, K. F., and Russin, J. S. 2001. Comparison of constitutive and inducible maize kernel proteins of genotypes resistant or susceptible to aflatoxin production. J. Food Prot. 64: 1785-1792.

Chen, Z.-Y., Brown, R. L., Damann, K. E., and Cleveland, T. E. 2007. Identification of maize kernel endosperm proteins associated with resistance to aflatoxin contamination by Aspergillus flavus. Phytopathology 97:1094-1103.

Chen, Z.-Y., Brown, R. L., Damann, K. E., and Cleveland, T. E. 2010. PR10 expression in maize and its effect on host resistance against Aspergillus flavus infection and aflatoxin production. Mol. Plant Pathol. 11:69-81.

Chen, Z.-Y., Brown, R. L., Menkir, A., and Cleveland, T. E. 2012. Identification of resistance-associated proteins in closely-related maize lines varying in aflatoxin accumulation. Mol. Breed. 30:53-68.

Chen, Z.-Y., Warburton, M. L., Hawkins, L., Wei, Q., Raruang, Y., Brown, R. L., Zhang, L., and Bhatnagar, D. 2016. Production of the $14 \mathrm{kDa}$ trypsin inhibitor protein is important for maize resistance against Aspergillus flavus infection/aflatoxin accumulation. World Mycotoxin J. 9:215-228.

Cotty, P. J. 1990. Effect of atoxigenic strains of Aspergillus flavus on aflatoxin contamination of developing cottonseed. Plant Dis. 74:233-235.

Cotty, P. J., and Bayman, P. 1993. Competitive exclusion of a toxigenic strain of Aspergillus flavus by an atoxigenic strain. Phytopathology 83:1283-1287.

Criseo, G., Urzì, C., Pernice, I., and Medici, M. A. 1990. Growth and aflatoxin production by Aspergillus flavus Link under cycling temperatures. Ital. J. Food Sci. 1:43-51.

Damann, K. E., Jr. 2015. Atoxigenic Aspergillus flavus biological control of aflatoxin contamination: What is the mechanism? World Mycotoxin J. 8:235-244.

Dobolyi, C., Sebok, F., Varga, J., Kocsube, S., Szigeti, G., Baranyi, N., Szecsi, A., Toth, B., Varga, M., Kriszt, B., Szoboszlay, S., Krifaton, C., and Kukolya, J. 2013. Occurrence of aflatoxin producing Aspergillus flavus isolates in maize kernel in Hungary. Acta Aliment. Budap. 42:451-459.

Dolezal, A. L., Shu, X., Obrian, G. R., Nielsen, D. M., Woloshuk, C. P., Boston, R. S., and Payne, G. A. 2014. Aspergillus flavus infection induces transcriptional and physical changes in developing maize kernels. Front. Microbiol. 5:384.

Dorner, J. W. 2004. Biological control of aflatoxin contamination of crops. J. Toxicol. Toxin Rev. 23:425-450.

Dorner, J. W. 2009. Development of biocontrol technology to manage aflatoxin contamination in peanuts. Peanut Sci. 36:60-67.

Dorner, J. W., and Lamb, M. C. 2006. Development and commercial use of afla-Guard $\AA$, an aflatoxin biocontrol agent. Mycotoxin Res. 22:33-38.

Ehrlich, K. C., and Cotty, P. J. 2004. An isolate of Aspergillus flavus used to reduce aflatoxin contamination in cottonseed has a defective polyketide synthase gene. Appl. Microbiol. Biotechnol. 65:473-478.

Ehrlich, K. C., Moore, G. G., Mellon, J. E., and Bhatnagar, D. 2015. Challenges facing the biological control strategy for eliminating aflatoxin contamination. World Mycotoxin J. 8:225-233.

European Commission. 1999. Opinion on the relationship between the use of plant protection products on food plants and the occurrence of mycotoxins in foods. European Commission SCP/RESI/063, Belgium.

European Commission. 2010. Commission regulation (EU) No 165/2010 amending regulation (EC) No 1881/2006 setting maximum levels for certain contaminants in foodstuffs as regards aflatoxins. Off. J. Eur. Union 50:8-12.

Fakhoury, A. M., and Woloshuk, C. P. 1999. Amy1, the $\alpha$-amylase gene of Aspergillus flavus: involvement in aflatoxin biosynthesis in maize kernels. Phytopathology 89:908-914.

Farfan, I. D. B., De La Fuente, G. N., Murray, S. C., Isakeit, T., Huang, P.-C., Warburton, M., Williams, P., Windham, G. L., and Kolomiets, M. 2015. Genome wide association study for drought, aflatoxin resistance, and important agronomic traits of maize hybrids in the sub-tropics. PLoS One 10:e0117737.

Fountain, J. C., Khera, P., Yang, L., Nayak, S. N., Scully, B. T., Lee, R. D., Chen, Z.-Y., Kemerait, R. C., Varshney, R. K., and Guo, B. 2015. Resistance to Aspergillus flavus in maize and peanut: Molecular biology, breeding, environmental stress, and future perspectives. Crop J. 3:229-237.

Fountain, J. C., Koh, J., Yang, L., Pandey, M. K., Nayak, S. N., Bajaj, P., Zhuang, W., Kemerait, R. C., Lee, R. D., Chen, S., Varshney, R. K., and Guo, B. 2018. Proteome analysis of Aspergillus flavus isolate-specific responses to oxidative stress in relationship to aflatoxin production capability. Sci. Rep. 8:3430. 
Gao, C. 2018. The future of CRISPR technologies in agriculture. Nat. Rev. Mol. Cell Biol. 19:275-276.

Geiser, D. M., Dorner, J. W., Horn, B. W., and Taylor, J. W. 2000. The phylogenetics of mycotoxin and sclerotium production in Aspergillus flavus and Aspergillus oryzae. Fungal Genet. Biol. 31:169-179.

Gilbert, M. K., Majumdar, R., Rajasekaran, K., Chen, Z.-Y., Wei, Q., Sickler, C. M., Lebar, M. D., Cary, J. W., Frame, B. R., and Wang, K. 2018. RNA interference-based silencing of the alpha-amylase (amyl) gene in Aspergillus flavus decreases fungal growth and aflatoxin production in maize kernels. Planta 247:1465.

Giorni, P., Battilani, P., Pietri, A., and Magan, N. 2008. Effect of aw and $\mathrm{CO}_{2}$ level on Aspergillus flavus growth and aflatoxin production in high moisture maize post-harvest. Int. J. Food Microbiol. 122:109-113.

Giorni, P., Bertuzzi, T., and Battilani, P. 2016. Aflatoxin in maize, a multifaceted answer of Aspergillus flavus governed by weather, host-plant and competitor fungi. J. Cereal Sci. 70:256-262.

Giorni, P., Magan, N., and Battilani, P. 2009a. Environmental factors modify carbon nutritional patterns and niche overlap between Aspergillus flavus and Fusarium verticillioides strains from maize. Int. J. Food Microbiol. 130:213-218.

Giorni, P., Pietri, A., Magan, N., and Battilani, P. 2009b. Control of the development of Aspergillus flavus in maize during post-harvest. Tec. Molit. 60:261-267.

Grubisha, L. C., and Cotty, P. J. 2010. Genetic isolation among sympatric vegetative compatibility groups of the aflatoxin-producing fungus Aspergillus flavus. Mol. Ecol. 19:269-280.

Hawkins, L. K., Windham, G. L., and Williams, W. P. 2008. Occurrence of aflatoxin in three maize (Zea mays L.) hybrids over 5 years in Northern Mississippi. Mycopathologia 165:165-171.

Hell, K., and Mutegi, C. 2011. Aflatoxin control and prevention strategies in key crops of sub-Saharan Africa. Afr. J. Microbiol. Res. 5:459-466.

Horn, B. W. 2005. Ecology and population biology of aflatoxigenic fungi in soil. Pages 95-116 in: Aflatoxin and Food Safety. H. K. Abbas, ed. CRC Press, Boca Raton, FL.

Horn, B. W., Gell, R. M., Singh, R., Sorensen, R. B., and Carbone, I. 2016. Sexual reproduction in Aspergillus flavus sclerotia: Acquisition of novel alleles from soil populations and uniparental mitochondrial inheritance. PLoS One 11:e0146169.

Horn, B. W., Moore, G. G., and Carbone, I. 2009b. Sexual reproduction in Aspergillus flavus. Mycologia 101:423-429.

Horn, B. W., Moore, G. G., and Carbone, I. 2011. Sexual reproduction in aflatoxin-producing Aspergillus nomius. Mycologia 103:174-183.

Horn, B. W., Olarte, R. A., Peterson, S. W., and Carbone, I. 2013. Sexual reproduction in Aspergillus tubingensis from section Nigri. Mycologia 105: 1153-1163.

Horn, B. W., Ramirez-Prado, J. H., and Carbone, I. 2009a. Sexual reproduction and recombination in the aflatoxin-producing fungus Aspergillus parasiticus. Fungal Genet. Biol. 46:169-175.

Hruska, Z., Yao, H., Kincaid, R., Darlington, D., Brown, R. L., Bhatnagar, D., and Cleveland, T. E. 2013. Fluorescence imaging spectroscopy (FIS) for comparing spectra from corn ears naturally and artificially infected with aflatoxin producing fungus. J. Food Sci. 78: T1313-T1320.

Hu, S., Stroshine, R. L., and Ileleji, K. 2017. Differences in kernel shape, size, and density between healthy kernels and mold discolored kernels and their relationship to reduction in aflatoxin levels in a sample of shelled corn. Appl. Eng. Agric. 33:421-431.

Huang, C., Jha, A., Sweany, R., DeRobertis, C., and Damann, K. E., Jr. 2011. Intraspecific aflatoxin inhibition in Aspergillus flavus is thigmoregulated, independent of vegetative compatibility group and is strain dependent. PLoS One 6:e23470.

Johnson, E. T., Proctor, R. H., Dunlap, C. A., and Busman, M. 2018. Reducing production of fumonisin mycotoxins in Fusarium verticillioides by RNA interference. Mycotoxin Res. 34:29-37.

Jolly, P. E., Jiang, Y., Ellis, W. O., Wang, J. S., and Afriyie-Gyawu, E. 2008. Modulation of the human immune system by aflatoxin. Pages 41-52 in: Mycotoxins: Detection Methods, Management, Public Health and Agricultural Trade. J. F. Leslie, R. Bandyopadhyay, and A. Visconti, eds. CAB International, Wallingford, UK.

Kabak, B., Dobson, A. D. W., and Var, I. 2006. Strategies to prevent mycotoxin contamination of food and animal feed: A review. Crit. Rev. Food Sci. Nutr. 46:593-619.

Katoch, R., and Thakur, N. 2013. Advances in RNA interference technology and its impact on nutritional improvement, disease and insect control in plants. Appl. Biochem. Biotechnol. 169:1579-1605.

Kebede, H., Abbas, H. K., Fisher, D. K., and Bellaloui, N. 2012. Relationship between aflatoxin contamination and physiological responses of corn plants under drought and heat stress. Toxins (Basel) 4:1385-1403.
Kelley, R. Y., Gresham, C., Harper, J., Bridges, S. M., Warburton, M. L., Hawkins, L. K., Pechanova, O., Peethambaran, B., Pechan, T., Luthe, D. S., Mylroie, J. E., Ankala, A., Ozkan, S., Henry, W. B., and Williams, W. P. 2010. Integrated database for identifying candidate genes for Aspergillus flavus resistance in maize. BMC Bioinformatics 11:S25.

Kensler, T. W., Roebuck, B. D., Wogan, G. N., and Groopman, J. D. 2011. Aflatoxin: A 50-year odyssey of mechanistic and translational toxicology. Toxicol. Sci. 120:S28-S48.

Khlangwiset, P., Shephard, G. S., and Wu, F. 2011. Aflatoxins and growth impairment: A review. Crit. Rev. Toxicol. 41:740-755.

Ladeira, C., Frazzoli, C., and Orisakwe, O. E. 2017. Engaging one health for non-communicable diseases in Africa: Perspective for mycotoxins. Front. Public Health 5:266.

Lahouar, A., Marin, S., Crespo-Sempere, A., Saïd, S., and Sanchis, V. 2016. Effects of temperature, water activity and incubation time on fungal growth and aflatoxin $\mathrm{B}_{1}$ production by toxigenic Aspergillus flavus isolates on sorghum seeds. Rev. Argent. Microbiol. 48:78-85.

Lewis, L., Onsongo, M., Njapau, H., Schurz-Rogers, H., Luber, G., Kieszak, S., Nyamongo, J., Backer, L., Dahiye, A. M., Misore, A., DeCock, K., and Rubin, C. 2005. Aflatoxin contamination of commercial maize products during an outbreak of acute aflatoxicosis in Eastern and Central Kenya. Environ. Health Perspect. 113:1763-1767.

Ling, K. H., Tung, C. M., Sheh, I. F., Wang, J. J., and Tung, T. C. 1968. Aflatoxin $\mathrm{B}_{1}$ in unrefined peanut oil and peanut products in Taiwan. $\mathrm{J}$. Formos. Med. Assoc. 67:309-314.

Lye, M. S., Ghazali, A. A., Mohan, J., Alwin, N., and Nair, R. C. 1995. An outbreak of acute hepatic encephalopathy due to severe aflatoxicosis in Malaysia. Am. J. Trop. Med. Hyg. 53:68-72.

Magan, N., and Medina, A. 2016. Integrating gene expression, ecology and mycotoxin production by Fusarium and Aspergillus species in relation to interacting environmental factors. World Mycotoxin J. 9:673-684.

Majumdar, R., Rajasekaran, K., and Cary, J. W. 2017a. RNA interference (RNAi) as a potential tool for control of mycotoxin contamination in crop plants: Concepts and considerations. Front. Plant Sci. 8:200.

Majumdar, R., Rajasekaran, K., Sickler, C., Lebar, M., Musungu, B. M., Fakhoury, A. M., Payne, G. A., Geisler, M., Carter-Wientjes, C., Wei, Q., Bhatnagar, D., and Cary, J. W. 2017b. The pathogenesis-related maize seed (PRms) gene plays a role in resistance to Aspergillus flavus infection and aflatoxin contamination. Front. Plant Sci. 8:1758.

Marsh, S. F., and Payne, G. A. 1984. Preharvest infection of corn silks and kernels by Aspergillus flavus. Phytopathology 74:1284-1289.

Masanga, J. O., Matheka, J. M., Omer, R. A., Ommeh, S. C., Monda, E. O., and Alakonya, A. E. 2015. Downregulation of transcription factor aflR in Aspergillus flavus confers reduction to aflatoxin accumulation in transgenic maize with alteration of host plant architecture. Plant Cell Rep. 34: 1379-1387.

Masuoka, P., Chamberlin, J., and Elias, M. 2010. Modeling the distribution and probability of aflatoxin occurrence using environmental data. International Food Policy Research Institute. http://cdm15738.contentdm.oclc.org/utils/getfile/collection/p15738coll2/id/4956/filename/ 4957.pdf

Mauro, A., Garcia-Cela, E., Pietri, A., Cotty, P. J., and Battilani, P. 2018. Biological control products for aflatoxin prevention in Italy: Commercial field evaluation of atoxigenic Aspergillus flavus active ingredients. Toxins (Basel) 10:30

Medina, A., Akbar, A., Baazeem, A., Rodriguez, A., and Magan, N. 2017b. Climate change, food security and mycotoxins: do we know enough? Fungal Biol. Rev. 31:143-154.

Medina, A., Gilbert, M. K., Mack, B. M., Obrian, G. R., Rodriguez, A., Bhatnagar, D., Payne, G., and Magan, N. 2017a. Interactions between water activity and temperature on the Aspergillus flavus transcriptome and aflatoxin $\mathrm{B}_{1}$ production. Int. J. Food Microbiol. 256:36-44.

Medina, A., Rodriguez, A., and Magan, N. 2014. Effect of climate change on Aspergillus flavus and aflatoxin $\mathrm{B}_{1}$ production. Front. Microbiol. 5:348.

Mehl, H. L., Jaime, R., Callicott, K. A., Probst, C., Garber, N. P., Ortega-Beltran, A., Grubisha, L. C., and Cotty, P. J. 2012. Aspergillus flavus diversity on crops and in the environment can be exploited to reduce aflatoxin exposure and improve health. Ann. N.Y. Acad. Sci. 1273:7-17.

Moore, G. G. 2010. Global population structure and aflatoxin chemotype diversity in Aspergillus section Flavi. Ph.D. Thesis. North Carolina State University, Raleigh, NC.

Moore, G. G., Elliott, J. L., Singh, R., Horn, B. W., Dorner, J. W., Stone, E. A., Chulze, S. N., Barros, G. G., Naik, M. K., Wright, G. C., Hell, K., and Carbone, I. 2013. Sexuality generates diversity in the aflatoxin gene cluster: evidence on a global scale. PLoS Pathog. 9:e1003574.

Moore, G. G., Olarte, R. A., Horn, B. W., Elliott, J. L., Singh, R., O’Neal, C. J., and Carbone, I. 2017. Global population structure and adaptive evolution of aflatoxin-producing fungi. Ecol. Evol. 7:9179-9191. 
Moore, G. G., Singh, R., Horn, B. W., and Carbone, I. 2009. Recombination and lineage-specific gene loss in the aflatoxin gene cluster of Aspergillus flavus. Mol. Ecol. 18:4870-4887.

Moore, K. G., Price, M. S., Boston, R. S., Weissinger, A. K., and Payne, G. A. 2004. A chitinase from Tex6 maize kernels inhibits growth of Aspergillus flavus. Phytopathology 94:82-87.

Musungu, B. M., Bhatnagar, D., Brown, R. L., Payne, G. A., Obrian, G., Fakhoury, A. M., and Geisler, M. 2016. A network approach of gene coexpression in the Zea mays/Aspergillus flavus pathosystem to map host/ pathogen interaction pathways. Front. Genet. 7:206.

Mylroie, J. E., Warburton, M. L., and Wilkinson, J. R. 2013. Development of a gene-based marker correlated to reduced aflatoxin accumulation in maize. Euphytica 194:431-441.

Mytox. 2016. Aflatoxin outbreak in Tanzania. Available at https://mytox.be/ aflatoxin-outbreak-tanzania

Ngindu, A., Kenya, P. R., Ochieng, D. M., Omondi, T. N., Ngare, W., Gatei, D., Johnson, B. K., Ngira, J. A., Nandwa, H., Jansen, A. J., Kaviti, J. N., and Arap Siongok, T. 1982. Outbreak of acute hepatitis caused by aflatoxin poisoning in Kenya. Lancet 319:1346-1348.

Nunes, C. C., and Dean, R. A. 2012. Host-induced gene silencing: A tool for understanding fungal host interaction and for developing novel disease control strategies. Mol. Plant Pathol. 13:519-529.

Okoth, S., Rose, L. J., Ouko, A., Beukes, I., Sila, H., Mouton, M., Flett, B. C., Makumbi, D., and Viljoen, A. 2017. Field evaluation of resistance to aflatoxin accumulation in maize inbred lines in Kenya and South Africa. J. Crop Improv. 31:862-878.

Olarte, R. A., Horn, B. W., Dorner, J. W., Monacell, J. T., Singh, R., Stone, E. A., and Carbone, I. 2012. Effect of sexual recombination on population diversity in aflatoxin production by Aspergillus flavus and evidence for cryptic heterokaryosis. Mol. Ecol. 21:1453-1476.

Olarte, R. A., Horn, B. W., Singh, R., and Carbone, I. 2015a. Sexual recombination in Aspergillus tubingensis. Mycologia 107:307-312.

Olarte, R. A., Worthington, C. J., Horn, B. W., Moore, G. G., Singh, R., Monacell, J. T., Dorner, J. W., Stone, E. A., Xie, D. Y., and Carbone, I. 2015b. Enhanced diversity and aflatoxigenicity in interspecific hybrids of Aspergillus flavus and Aspergillus parasiticus. Mol. Ecol. 24:1889-1909.

Ortega-Beltran, A., Guerrero-Herrera, M. D. J., Ortega-Corona, A., Vidal-Martinez, V. A., and Cotty, P. J. 2014. Susceptibility to aflatoxin contamination among maize landraces from Mexico. J. Food Prot. 77: 1554-1562.

Ortiz, M. P., Barros, G. G., Reynoso, M. M., Torres, A. M., Chulze, S. N., and Ramirez, M. L. 2011. Soil populations of Aspergillus section Flavi from the main and new peanut growing areas in Argentina. ISM Conference 2011. Strategies to reduce the impact of mycotoxins in Latin America in a global context. ISM Abstract Book.

Ostrý, V., Malîr, F., and Pfohl-Leszkowicz, A. 2015. Comparative data concerning aflatoxin contents in Bt maize and non-Bt isogenic maize in relation to human and animal health-A review. Acta Vet. Brno 84:47-53.

Otsuki, T., Wilson, J. S., and Sewadeh, M. 2001. Saving two in a billion: Quantifying the trade effect of European food safety standards on African exports. Food Policy 26:495-514.

Palumbo, J. D., Baker, J. L., and Mahoney, N. E. 2006. Isolation of bacterial antagonists of Aspergillus flavus from almonds. Microbiol. Ecol. 52:45-52.

Papa, K. E. 1973. Parasexual cycle in Aspergillus flavus. Mycologia 65: 1201-1205.

Parsons, M. W., and Munkvold, G. P. 2012. Effects of planting date and environmental factors on fusarium ear rot symptoms and fumonisin $\mathrm{B}_{1}$ accumulation in maize grown in six North American locations. Plant Pathol. 61:1130-1142.

Paulussen, C., Hallsworth, J. E., Álvarez-Pérez, S., Nierman, W. C., Hamill, P. G., Blain, D., Rediers, H., and Lievens, B. 2016. Ecology of aspergillosis: Insights into the pathogenic potency of Aspergillus fumigatus and some other Aspergillus species. Microbiol. Biotechnol. 10:296-322.

Payne, G. A. 1998. Process of contamination by aflatoxin producing fungi and their impacts on crops. Pages 279-306 in: Mycotoxins in Agriculture and Food Safety. K. K. Sinha and D. Bhatnagar, eds. Marcel Dekker Inc., New York.

Payne, G. A., Hagler, W. M., Jr., and Adkins, C. R. 1988. Aflatoxin accumulation in inoculated ears of field-grown maize. Plant Dis. 72:422-424.

Payne, G. A., and Widstrom, N. W. 1992. Aflatoxin in maize. Crit. Rev. Plant Sci. 10:423-440.

Piva, G., Battilani, P., and Pietri, A. 2006. Emerging issues in southern Europe: Aflatoxins in Italy. Pages 139-153 in: The Mycotoxin Factbook. Food \& Feed Topics. D. Barug, D., Bhatnagar, H. P. van Egmond, J. W. van der Kamp, W. A. van Osenbruggen, and A. Visconti, eds. Wageningen Academic Publishers, The Netherlands.

Power, I. L., Dang, P. M., Sobolev, V. S., Orner, V. A., Powell, J. L., Lamb, M. C., and Arias, R. S. 2017. Characterization of small RNA populations in non-transgenic and aflatoxin-reducing-transformed peanut. Plant Sci. 257: $106-125$

Prasad, K., Bhatnagar-Mathur, P., Waliyar, F., and Sharma, K. K. 2013. Overexpression of a chitinase gene in transgenic peanut confers enhanced resistance to major soil borne and foliar fungal pathogens. J. Plant Biochem. Biotechnol. 22:222-233.

Price, M. S., Conners, S. B., Tachdjian, S., Kelly, R. M., and Payne, G. A. 2005. Aflatoxin conducive and non-conducive growth conditions reveal new gene associations with aflatoxin production. Fungal Genet. Biol. 42: 506-518.

Probst, C., Bandyopadhyay, R., and Cotty, P. J. 2014. Diversity of aflatoxinproducing fungi and their impact on food safety in sub-Saharan Africa. Int. J. Food Microbiol. 174:113-122.

Probst, C., Njapau, H., and Cotty, P. J. 2007. Outbreak of an acute aflatoxicosis in Kenya in 2004: Identification of the causal agent. Appl. Environ. Microbiol. 73:2762-2764.

Rajasekaran, K., Jaynes, J. M., and Cary, J. W. 2009. Transgenic expression of lytic peptides in food and feed crops to control phytopathogens and preharvest mycotoxin contamination. Pages 119-142 in: Mycotoxin prevention and control in agriculture. M. Appell, D. F. Kendra, and M. W. Trucksess, eds. American Chemical Society, Washington, D.C.

Rajasekaran, K., Sayler, R. J., Sickler, C. M., Majumdar, R., Jaynes, J., and Cary, J. W. 2018. Control of Aspergillus flavus growth and aflatoxin production in transgenic maize kernels expressing a tachyplesin-derived synthetic peptide, AGM182. Plant Sci. 270:150-156

Ramirez-Prado, J. H., Moore, G. G., Horn, B. W., and Carbone, I. 2008. Characterization and population analysis of the mating-type genes in Aspergillus flavus and Aspergillus parasiticus. Fungal Genet. Biol. 45: 1292-1299.

Reverberi, M., Punelli, M., Scala, V., Scarpari, M., Uva, P., Mentzen, W. I., Dolezal, A. L., Woloshuk, C., Pinzari, F., Fabbri, A. A., Fanelli, C., and Payne, G. A. 2013. Genotypic and phenotypic versatility of Aspergillus flavus during maize exploitation. PLoS One 8:e68735.

Sanchis, V., and Magan, N. 2004. Environmental conditions affecting mycotoxins. Pages 174-189 in: Mycotoxins in Food. N. Magan and M. Olsen, eds. Woodhead Publishing, Cambridge, England.

Scheidegger, K. A., and Payne, G. A. 2005. Unlocking the secrets behind secondary metabolism: a review of Aspergillus flavus from pathogenicity to functional genomics. Pages 137-166 in: Aflatoxin and Food Safety. H. K. Abbas, ed. Taylor \& Francis Group, Boca Raton, FL.

Schubert, M., Houdelet, M., Kogel, K.-H., Fischer, R., Schillberg, S., and Nölke, G. 2015. Thanatin confers partial resistance against aflatoxigenic fungi in maize (Zea mays). Transgenic Res. 24:885-895.

Shank, R. C., Bourgeois, C. H., Keschamras, N., and Chandavimol, P. 1971. Aflatoxins in autopsy specimens from Thai children with an acute disease of unknown aetiology. Food Cosmet. Toxicol. 9:501-507.

Sharma, K. K., Pothana, A., Prasad, K., Shah, D., Kaur, J., Bhatnagar, D., Chen, Z.-Y., Raruang, Y., Cary, J. W., Rajasekaran, K., Sudini, H. K., and Bhatnagar-Mathur, P. 2018. Peanuts that keep aflatoxin at bay: A threshold that matters. Plant Biotechnol. J. 16:1024-1033.

Shephard, G. S. 2018. Aflatoxins in peanut oil: Food safety concerns. World Mycotoxin J. 11:149-158.

Shu, X., Livingston, D. P., Franks, R. G., Boston, R. S., Woloshuk, C. P., and Payne, G. A. 2015. Tissue-specific gene expression in maize seeds during colonization by Aspergillus flavus and Fusarium verticillioides. Mol. Plant Pathol. 16:662-674.

Shu, X., Livingston, D. P., Woloshuk, C. P., and Payne, G. A. 2017. Comparative histological and transcriptional analysis of maize kernels infected with Aspergillus flavus and Fusarium verticillioides. Front. Plant Sci. 8: 2075.

Stasiewicz, M. J., Falade, T. D. O., Mutuma, M., Mutiga, S. K., Harvey, J. J. W., Fox, G., Pearson, T. C., and Muthomi, J. W. 2017. Multi-spectral kernel sorting to reduce aflatoxins and fumonisins in Kenyan maize. Food Control 78:203-214.

Strosnider, H., Azziz-Baumgartner, E., Banziger, M., Bhat, R. V., Breiman, R., Brune, M. N., DeCock, K., Dilley, A., Groopman, J., Hell, K., Henry, S. H., Jeffers, D., Jolly, C., Jolly, P., Kibata, G. N., Lewis, L., Liu, X., Luber, G., McCoy, L., Mensah, P., Miraglia, M., Misore, A., Njapau, H., Ong, C. N., Onsongo, M. T., Page, S. W., Park, D., Patel, M., Phillips, T., Pineiro, M., Pronczuk, J., Rogers, H. S., Rubin, C., Sabino, M., Schaafsma, A., Shephard, G., Stroka, J., Wild, C., Williams, J. T., and Wilson, D. 2006. Workgroup report: public health strategies for reducing aflatoxin exposure in developing countries. Environ. Health Perspect. 114:1898-1903.

Sundaresha, S., Manoj Kumar, A., Rohini, S., Math, S. A., Keshamma, E., Chandrasekhar, S. C., and Udayakumar, M. 2010. Enhanced protection against two major fungal pathogens of groundnut, Cercospora arachidicola and Aspergillus flavus in transgenic groundnut over-expressing a tobacco $\beta$-1-3 glucanase. Eur. J. Plant Pathol. 126:497-508. 
Tatsadjieu, N. L., Yaouba, A., Nukenine, E. N., Ngassoum, M. B., and Mbofung, C. M. F. 2010. Comparative study of the simultaneous action of three essential oils on Aspergillus flavus and Sitophilus zeamais Motsch. Food Control 21:186-190.

Thakare, D., Zhang, J., Wing, R. A., Cotty, P. J., and Schmidt, M. A. 2017. Aflatoxin-free transgenic maize using host-induced gene silencing. Sci. Adv. 3:e1602382.

Tiwari, S., and Shankar, J. 2018. Integrated proteome and HPLC analysis revealed quercetin-mediated inhibition of aflatoxin B1 biosynthesis in Aspergillus flavus. 3 Biotech 8:47.

Torres, A. M., Barros, G. G., Palacios, S. A., Chulze, S. N., and Battilani, P. 2014. Review on pre- and post-harvest management of peanuts to minimize aflatoxin contamination. Food Res. Int. 62:11-19.

Udomkun, P., Wiredu, A. N., Nagle, M., Muller, J., Vanlauwe, B., and Bandyopadhyay, R. 2017. Innovative technologies to manage aflatoxins in foods and feeds and the profitability of application-A review. Food Control $76: 127-138$

Villers, P. 2014. Aflatoxins and safe storage. Front. Microbiol. 5:158.

Waliyar, F., Kumar, P. L., Traoré, A., Ntare, B. R., Diarra, B., and Kodio, O. 2008. Pre- and postharvest management of aflatoxin contamination in peanuts. Pages 209-218 in: Mycotoxins: Detection Methods, Management, Public Health and Agricultural Trade. J. F. Leslie, R. Bandyopadhyay, and A. Visconti, eds. CAB International/Cromwell Press, Trowbridge, UK.

Wang, S., Park, Y. S., Yang, Y., Borrego, E. J., Isakeit, T., Gao, X., and Kolomiets, M. V. 2017. Seed-derived ethylene facilitates colonization but not aflatoxin production by Aspergillus flavus in maize. Front. Plant Sci. 8:415.

Warburton, M. L., Tang, J. D., Windham, G. L., Hawkins, L. K., Murray, S. C., Xu, W., Boykin, D., Perkins, A., and Williams, W. P. 2015. Genome-wide association mapping of and aflatoxin accumulation resistance in maize. Crop Sci. 55:1857-1867.

Warburton, M. L., and Williams, W. P. 2014. Aflatoxin resistance in maize: What have we learned lately? Advances in Botany, vol. 2014. Article ID 352831 .
Warburton, M. L., Williams, W. P., Windham, G. L., Murray, S. C., Leigh, W. X., Hawkins, L. K., and Duran, J. F. 2013. Phenotypic and genetic characterization of a maize association mapping panel developed for the identification of new sources of resistance to and aflatoxin accumulation. Crop Sci. 53:2374-2383.

Weaver, M. A., Abbas, H. K., Brewer, M. J., Pruter, L. S., and Little, N. S. 2017. Integration of biological control and transgenic insect protection for mitigation of mycotoxins in corn. Crop Prot. 98:108-115.

Weber, E., and Bleiholder, H. 1990. Explanations of the BBCH decimal codes for the growth stages of maize, rape, faba beans, sunflowers and peas - with illustrations. Gesunde Pflanzen 42:308-321.

Widstrom, N. 1979. The role of insects and other plant pests in aflatoxin contamination of corn, cotton, and peanuts-A review. J. Environ. Qual. 8: 5-11.

Widstrom, N. W. 1996. The aflatoxin problem with corn grain. Adv. Agron. $56: 219-280$

Williams, W. P., Krakowsky, M. D., Scully, B. T., Brown, R. L., Menkir, A., Warburton, M. L., and Windham, G. L. 2014. Identifying and developing maize germplasm with resistance to accumulation of aflatoxins. World Mycotoxin J. 8:193-209.

Williams, W. P., Krakowsky, M. D., Windham, G. L., Balint-Kurti, P., Hawkins, L. K., and Henry, W. B. 2008. Identifying maize germplasm with resistance to aflatoxin accumulation. Toxin Rev. 27:319-345.

Wu, F. 2004. Mycotoxin risk assessment for the purpose of setting international regulatory standards. Environ. Sci. Technol. 38:4049-4055.

Wu, F., Bhatnagar, D., Bui-Klimke, T., Carbone, I., Hellmich, R., Munkvold, G., Paul, P., Payne, G., and Takle, E. 2011. Climate change impacts on mycotoxin risks in US maize. World Mycotoxin J. 4:79-93.

Wu, F., Groopman, J. D., and Pestka, J. J. 2014. Public health impacts of foodborne mycotoxins. Annu. Rev. Food Sci. Technol. 5:351-372.

Xie, Y.-R., Raruang, Y., Chen, Z.-Y., Brown, R. L., and Cleveland, T. E. 2015. ZmGns, a maize class I $\beta$-1,3-glucanase, is induced by biotic stresses and possesses strong antimicrobial activity. J. Integr. Plant Biol. 57:271-283. 